\title{
Taxonomic reassessment of Parasesarma (Crustacea: Brachyura: Decapoda: Sesarmidae) based on genetic and morphological comparisons, with the description of a new genus
}

\author{
ADNAN SHAHDADI ${ }^{1, *}$, SARA FRATINI ${ }^{2}$ and CHRISTOPH D. SCHUBART ${ }^{3}$ \\ ${ }^{1}$ Department of Marine Biology, Faculty of Marine Sciences and Technology, University of Hormozgan, \\ Bandar Abbas, Iran \\ ${ }^{2}$ Department of Biology, University of Florence, via Madonna del Piano 6, 50019 Sesto Fiorentino, Italy \\ ${ }^{3}$ Zoologie \& Evolutionsbiologie, Universität Regensburg, Regensburg 93040, Germany
}

Received 19 October 2019; revised 6 February 2020; accepted for publication 27 February 2020

\begin{abstract}
Parasesarma is a species-rich genus whose representatives are common in wetlands and mangroves of the IndoPacific. Morphologically, the genus is heterogeneous and has been postulated to constitute a polyphyletic taxon. In the present study, most species of Parasesarma are re-evaluated phylogenetically, using mitochondrial and nuclear molecular markers. The results show that the majority of the examined species cluster consistently with the type species Parasesarma plicatum. However, some species, among them the tree-climbing Parasesarma leptosoma, are clearly separated from this main clade of Parasesarma, forming a second stable monophyletic group, distinct from other known genera. Based on these results, and with additional support by morphological diagnoses highlighting consistent differences between the two species groups, we propose a new genus for the species clustering around $P$. leptosoma, proposing the new name Leptarma gen. nov.
\end{abstract}

ADDITIONAL KEYWORDS: molecular markers-new genus -Leptarma-phylogeny-sesarmid crabs-systematics.

\section{INTRODUCTION}

The brachyuran crab family Sesarmidae Dana, 1851, with 35 genera and $>250$ species ( $\mathrm{Ng}$ et al., 2008, 2019; De Grave et al., 2009; Naruse \& Ng, 2012; Brösing et al., 2014; Shahdadi \& Schubart, 2017), is the most speciesrich family in the subsection Thoracotremata Guinot, 1977. Although the family is a stable monophyletic taxon (see Schubart et al., 2006), it nevertheless has a complex taxonomic history (Guerao et al., 2004). For a long time, most of the sesarmid species were included in Sesarma Say, 1817 s.l. Later, this genus was split or subdivided into more genera and subgenera by $\mathrm{De}$ Man (1892, 1895), Tesch (1917) and Tweedie (1950). Serène \& Soh (1970) introduced a large number of new genera and established the taxonomic system that is

*Corresponding author. E-mail: adnan1361@gmail.com

[Version of record, published online 25 April 2020 ; http://zoobank.org/ urn:lsid:zoobank. org:pub:43B9C712- 8FB3-4606-8381-4ED90091D0A8] mostly valid today (see $\mathrm{Ng}$ et al., 2008). However, even after several recent revisionary studies (e.g. Davie, 1992, 1994, 2012; Schubart et al., 2009), there are still many ambiguities and taxonomic problems at different levels in the family, calling for further studies (see $\mathrm{Ng}$ et al., 2008).

Parasesarma De Man, 1895 was originally defined as a subgenus of Sesarma for nine species that were characterized by two or more rows of pectinated crests on the male chelar palm and lack of an epibranchial carapace tooth (see De Man, 1895: 181-217). Based on the same morphological characteristics, $\mathrm{Ng}$ et al. (2008) listed Parasesarma as a full genus, at that time with $\leq 28$ recognized species. Species of Parasesarma are among the most common Indo-Pacific Sesarmidae. They mostly inhabit estuarine wetlands, including mangrove swamps (Tan \& Ng, 1994; Shahdadi et al., 2018a), where they play an important role in nutrient cycling (Lee, 1998; Guerao et al., 2004; Cannicci et al., 2008; Lee, 2015). The genus was recently redefined and enlarged (Shahdadi \& Schubart, 2017), because of the 
additions and redescriptions of several species, and now comprises 71 recognized species (Rahayu \& Ng, 2010; Ng et al., 2016; Cannicci et al., 2017; Shahdadi \& Schubart, 2017; Li et al., 2018, 2019; Shahdadi et al., 2018a, b, 2019a; Fratini et al., 2019; Shih, et al., 2019). This makes it the most species-rich genus of the family Sesarmidae. However, it still includes poorly known species (Rahayu \& Ng, 2010; Rahayu \& Li, 2013; Shahdadi et al., 2018b; Fratini et al., 2019) and its phylogeny has not been resolved fully (Shahdadi \& Schubart, 2017).

Previous molecular phylogenetic studies on Parasesarma have detected and indicated the possibly polyphyletic status of the genus. For example, Parasesarma leptosoma (Hilgendorf, 1869) did not group with other included species of Parasesarma in a phylogenetic tree based on the mitochondrial $16 \mathrm{~S}$ and $12 \mathrm{~S}$ ribosomal RNA genes in the study by Schubart et al. (2006). Cannicci et al. (2017) found that P. leptosoma grouped closely together with Parasesarma gazi Cannicci, Innocenti, Fratini, 2017 in both mitochondrial and nuclear trees, but both were still separated from other congeners. Morphological heterogeneity among species of Parasesarma was also noticed by Rahayu $\& \mathrm{Ng}$ (2009), who identified two morphological groups according to length proportions of the ambulatory legs, i.e. short vs. long legs. Among the long-legged species, $P$. leptosoma is arguably the most distinctive (Li et $a l ., 2018)$. Overall, these and other lines of evidence reported by Shahdadi \& Schubart (2017) indicate that the species currently assigned to Parasesarma belong to more than one clade and that their phylogeny and taxonomy need to be re-evaluated.

For the present study, we examined almost all species of Parasesarma morphologically and genetically (with mitochondrial and nuclear molecular markers), with the following aims: (1) to investigate their phylogenetic relationships; (2) to reassess their taxonomy accordingly; and (3) to present new morphological diagnoses for newly defined taxa. This is the most extensive review carried out for the genus Parasesarma and solves taxonomically the deep phylogenetic divergence found among the members of the genus as so far described.

\section{MATERIAL AND METHODS}

\section{MATERIAL EXAMINED AND MORPHOLOGICAL ANALYSES}

Specimens were borrowed from or examined in the following museums: the Australian Museum (AM), Sydney, NSW, Australia; Queensland Museum (QM), Brisbane, Queensland, Australia; Western Australian Museum (WAM), Perth, WA, Australia; Museum Zoologi Bogor (MZB), Indonesian Institute of Sciences, Jakarta, Indonesia; National Museum of
Marine Biology and Aquarium (Crustacea Decapoda) (NMMBCD), Pingtung, Taiwan ROC; Natural History Museum and Institute (CBM), Chiba, Japan; Ryukyu University Museum (RUMF), Fujukan, Okinawa, Japan; Zoological Reference Collection (ZRC) of the Lee Kong Chian Natural History Museum, National University of Singapore, Singapore; US National Museum of Natural History (USNM), Smithsonian Institution, Washington, DC, USA; Academy of Natural Sciences of Drexel University (NASP), Philadelphia, PA, USA; Florida Museum of Natural History (UF), Gainesville. FL, USA; Forschungsinstitut und Museum Senckenberg (SMF), Frankfurt am Main, Germany [including material that was incorporated from the Zoologisches Museum der Universität Göttingen (ZMG)]; Zoologisches Museum Berlin (ZMB), Berlin, Germany; Zoologische Staatssammlung (ZSMA), Munich, Germany; Natural History Museum of the University of Florence (MZUF), Florence, Italy; Naturhistorisches Museum Wien (NHMW), Vienna, Austria; Naturalis Biodiversity Center (ex Rijksmuseum van Natuurlijke Historie; RMNH), Leiden, The Netherlands; Muséum National d'Histoire Naturelle (MNHN), Paris, France; Natural History Museum (NHM), London, UK. The holotype of Parasesarma palauense Takeda, 1971 was borrowed from Kitakyushu Museum of Natural History and Human History, Fukuoka, Japan (this specimen was formerly deposited in the Zoological Laboratory Kyushu University, ZLKU).

Except for Parasesarma exquisitum Dai \& Song, 1986 (for which no material was available) and Parasesarma aurifrons Li, Shih \& Ng, 2019, all species of Parasesarma were examined for the present paper (Table 1). The specimens were examined and described using a stereomicroscope (Leica S4E or Leica Wild Heerbrugg M8), and details of the male gonopods and female gonopores were examined with a photographic microscope (Keyence VHX500FXX). Maximum carapace widths and carapace lengths (in millimetres) were measured for all specimens (Table 1). The ratio of eyestalk length (esl; from the base of the posterior projection of the cornea to the base of the eyestalk) to maximum eyestalk width (esw) and the ratio of the length of the fourth pereiopod (P4) to carapace width (cw) were calculated for selected specimens only (Table 1). The measurements for the eyestalk morphometry were obtained using the program tpsDig 2.10 (Rohlf, 2006) from digital photographs (Fig. 1A). Morphometric measurements of the carapace and the pereiopod were obtained with digital callipers (Fig. 1B, C).

Data analyses and graphs were performed using IBM SPSS Statistics v.21. Photographs of the paratypes of $P$. exquisitum (catalogue number CB03317) and 


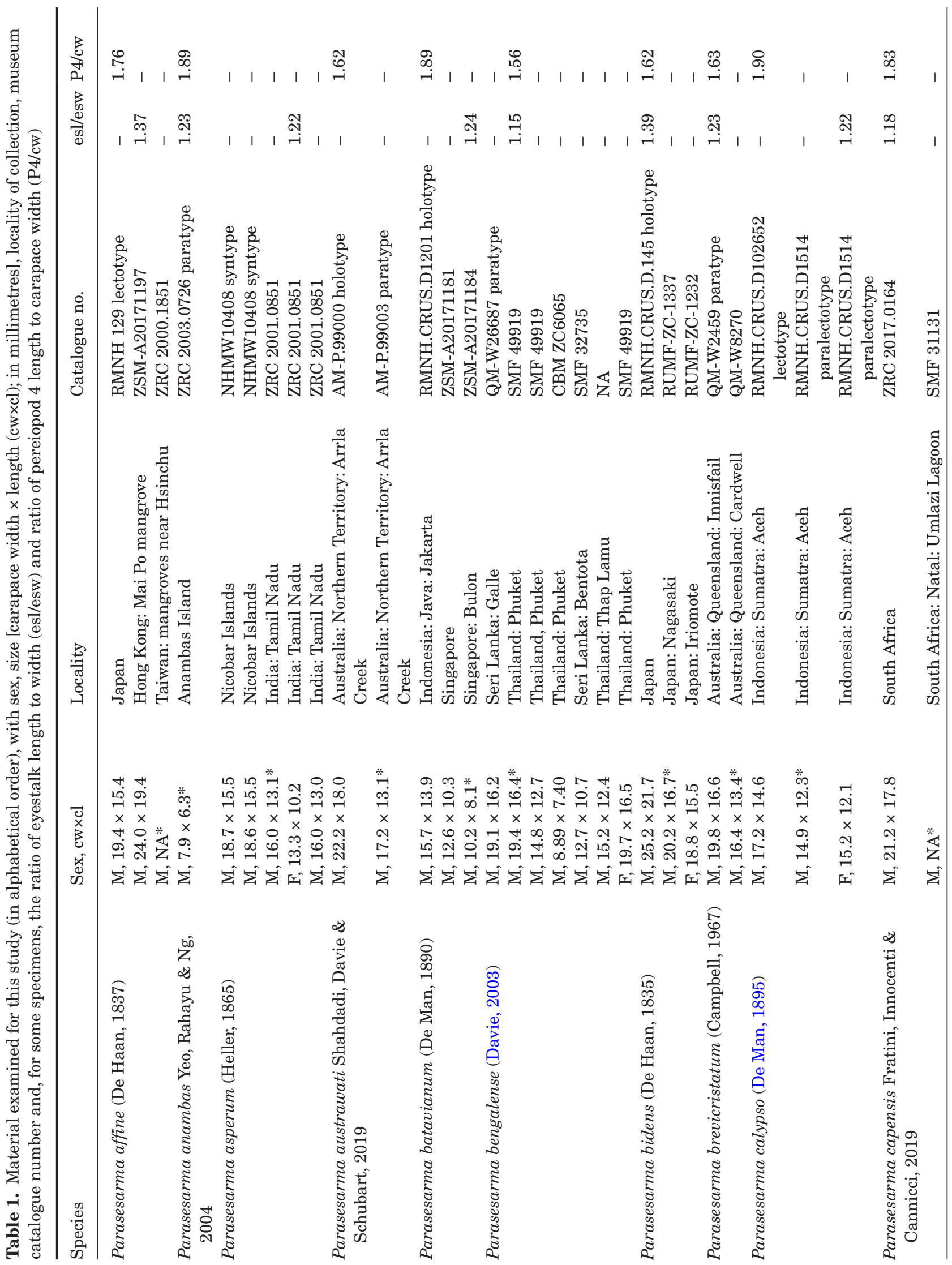




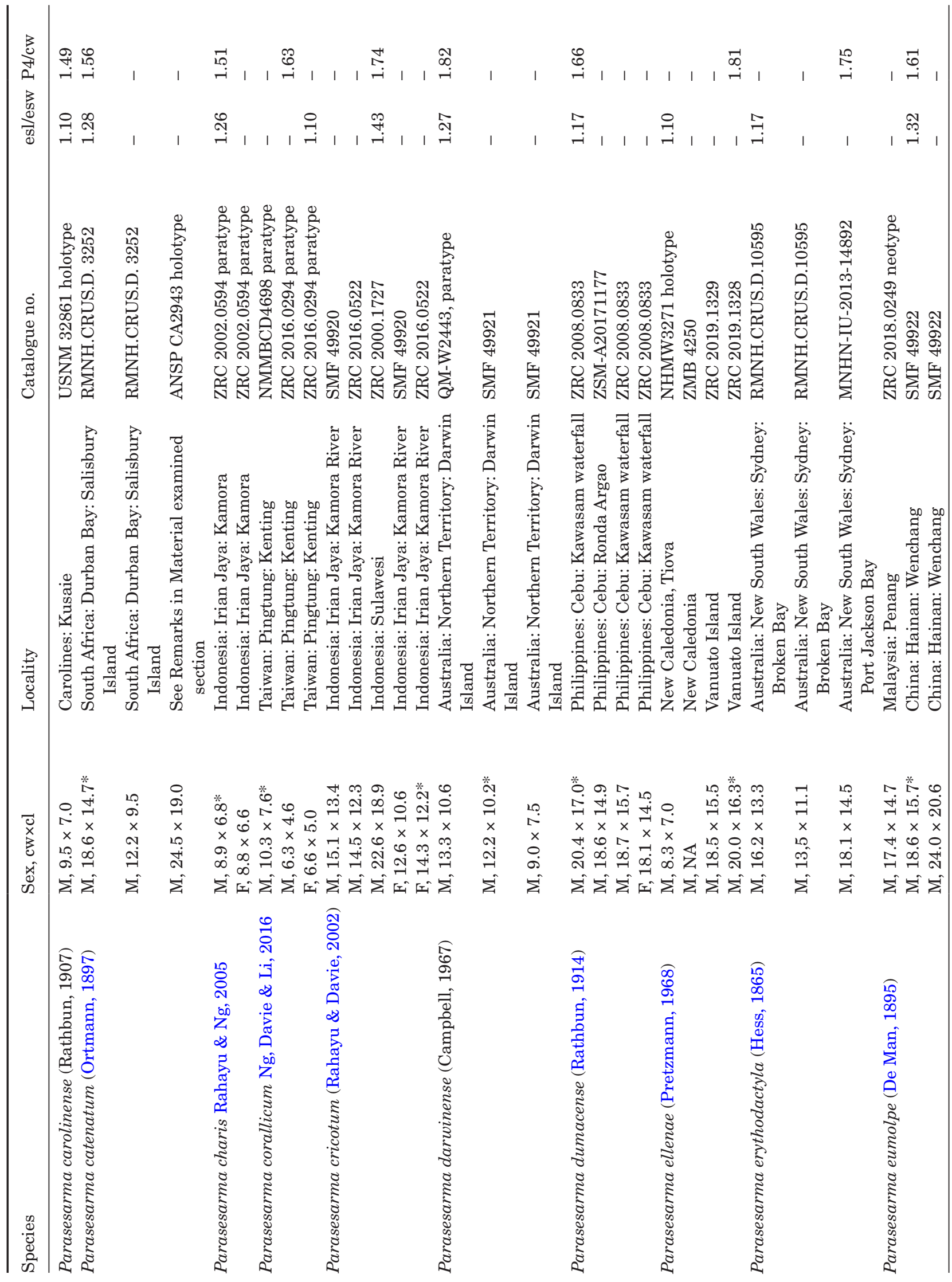




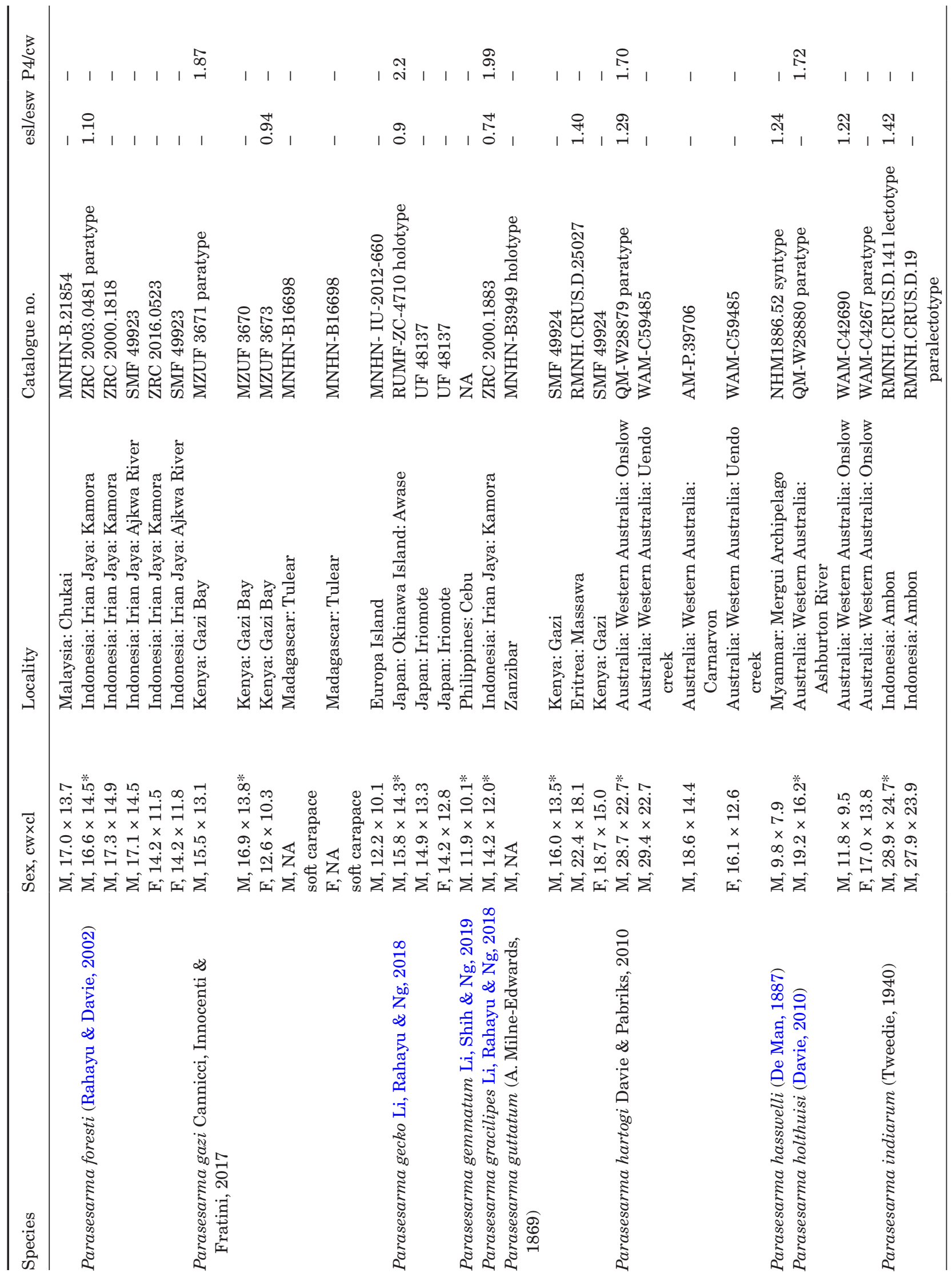




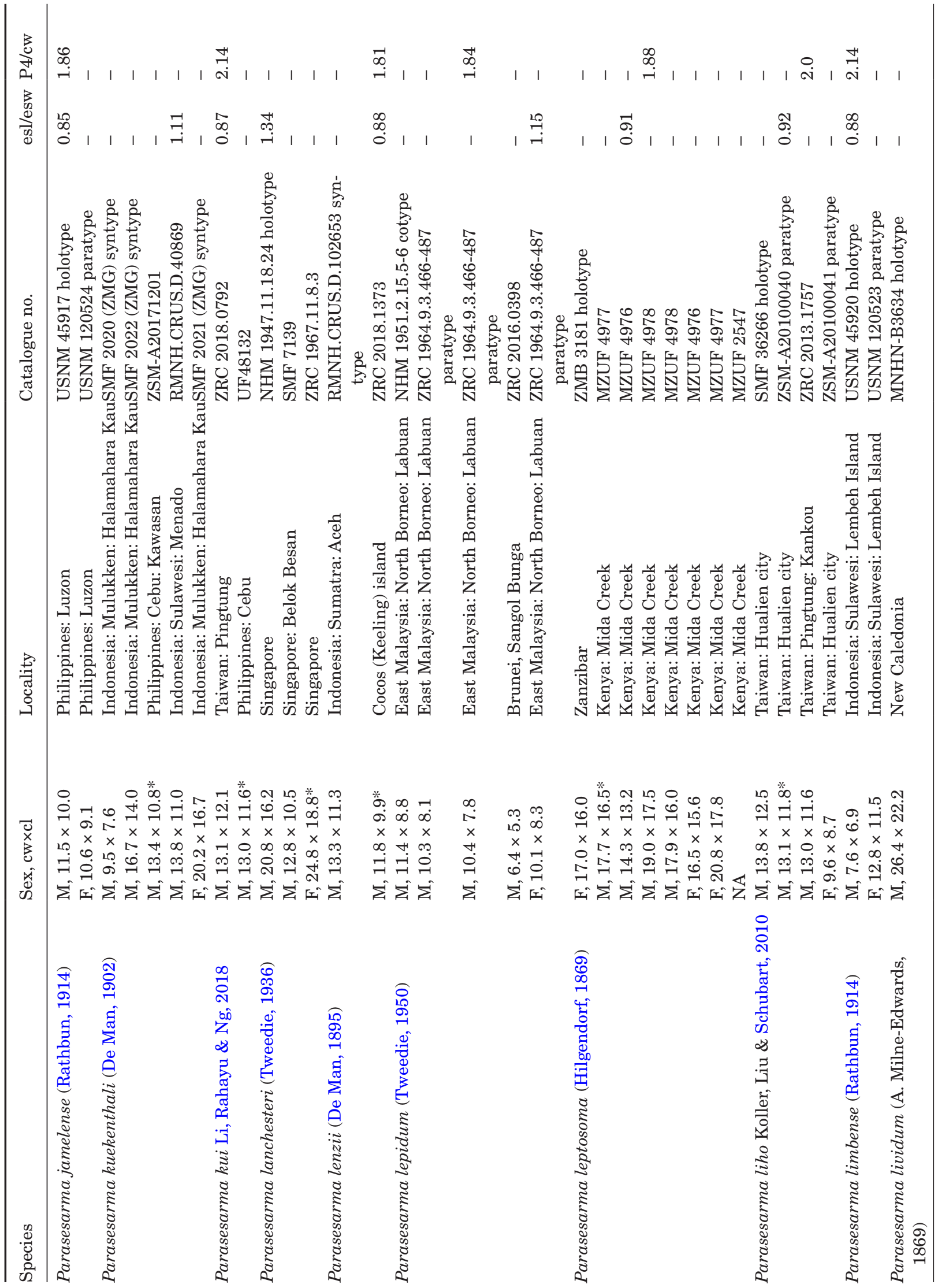




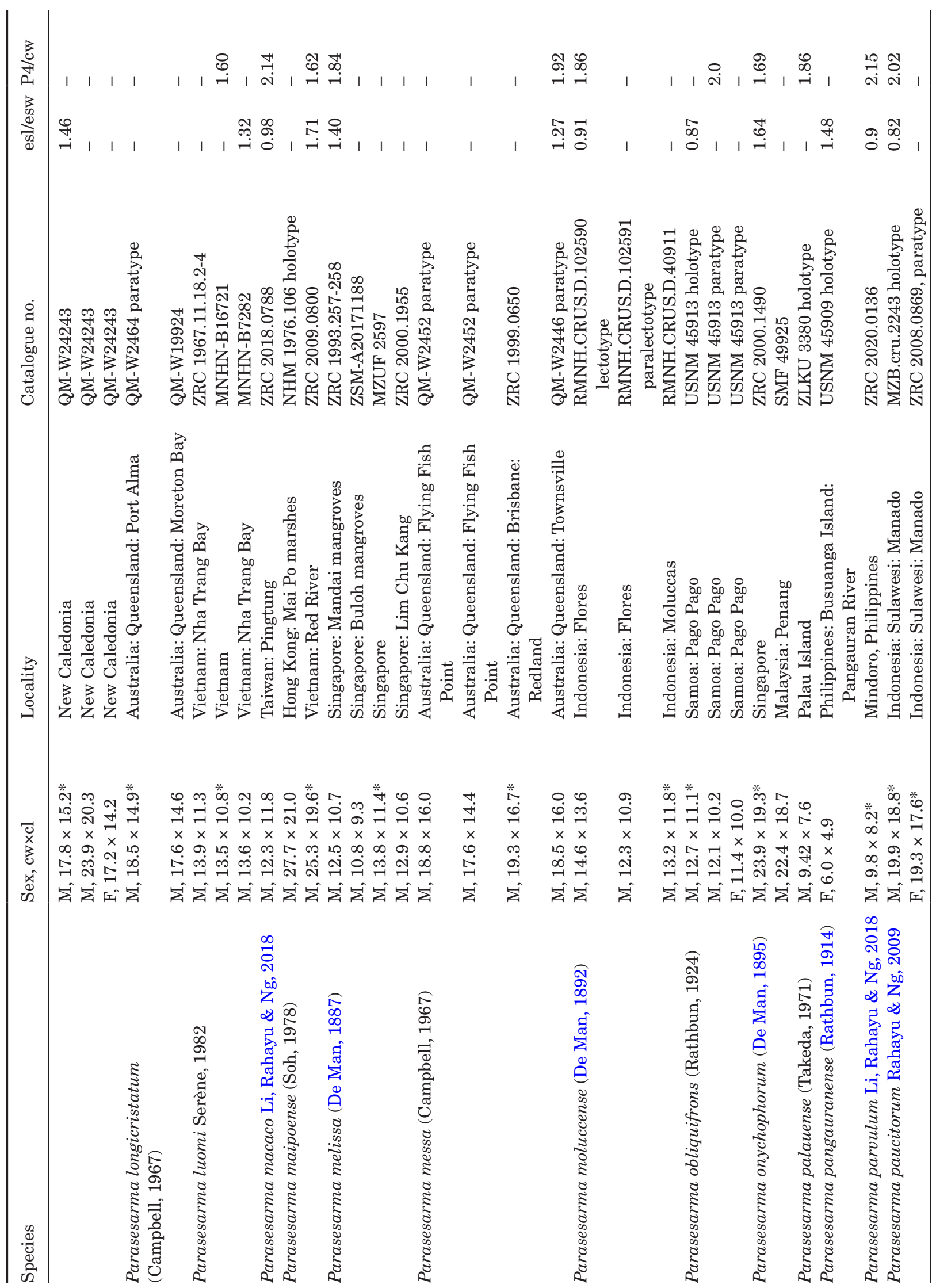




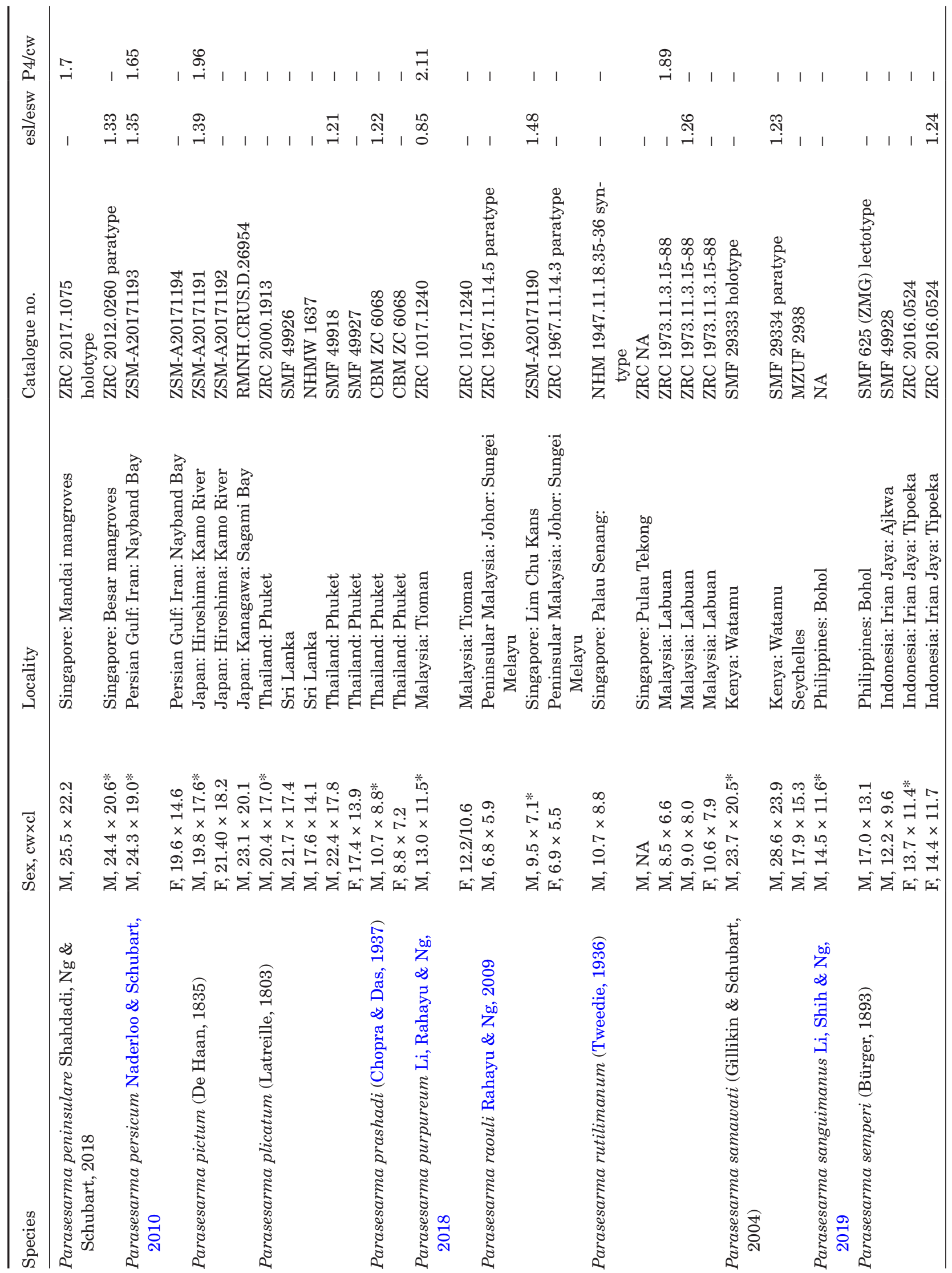




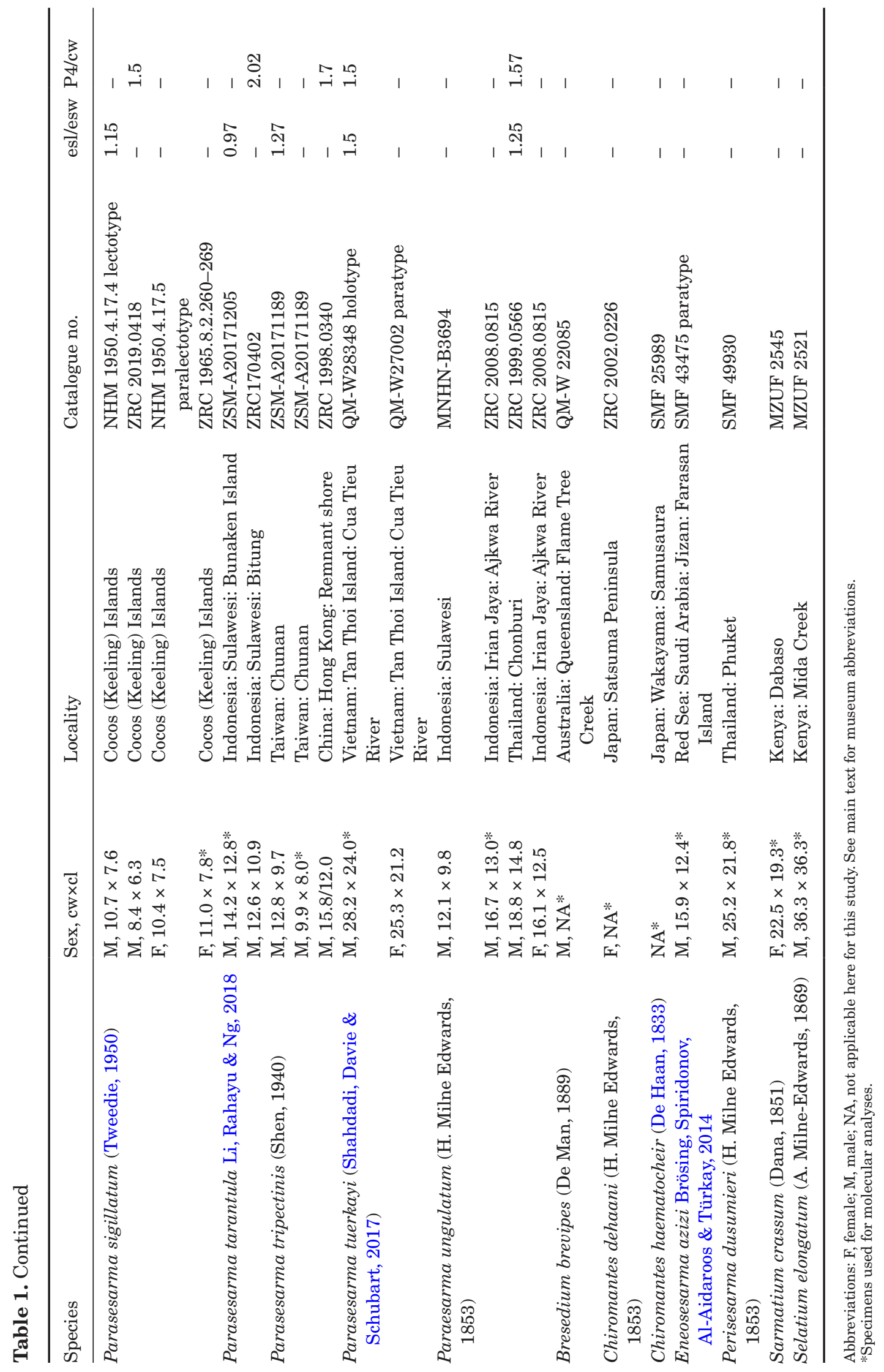



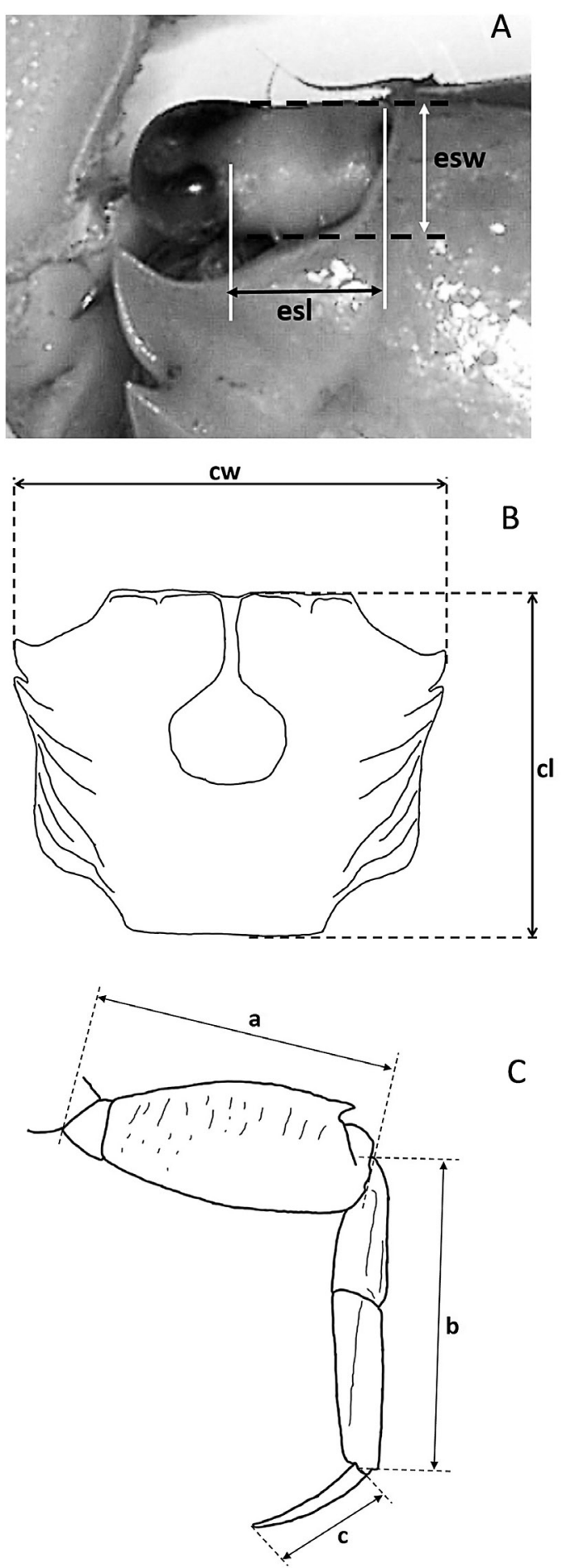

Figure 1. Diagrams of the morphometric characters used for this study. A, eyestalk. B, carapace: cw, carapace width, cl, carapace length. $\mathrm{C}$, fourth pereiopod $(\mathrm{P} 4): \mathrm{a}+\mathrm{b}+\mathrm{c}=\mathrm{P} 4$ length (ischium-dactylus).

Parasesarma tripectinis (Shen, 1940) (catalogue number CB03227-8; from Beijing Natural History Museum, Beijing, China) were kindly provided by our colleagues Ngan Kee Ng and Peter K. L. Ng (National University of Singapore).

The following abbreviations are used in the text: cl, carapace length; cw, carapace width; esl, eye stalk length; esw, eye stalk width; G1, male first gonopod; P, pereiopod.

\section{MoleCUlar ANALYSES}

Genomic DNA was isolated using a modified Puregene method (Gentra Systems, Minneapolis, MN, USA) or Mollusc DNA kit (Omega Bio-tek D3373-02, Norcross, Georgia, USA) from muscular leg tissue or female pleopods, using the manufacturers' protocols. In cases of old specimens or those fixed in formalin, the muscle tissues were soaked in GTE buffer (Glucose/Tris/ EDTA) overnight before starting the DNA extraction process (Shedlock et al., 1997) with the Mollusc DNA kit. For nine species [Parasesarma carolinense Rathbun, 1907, Parasesarma erythodactyla (Hess, 1865), Parasesarma hasswelli (De Man, 1887), Parasesarma jamelense (Rathbun, 1914), Parasesarma lepidum (Tweedie, 1950), Parasesarma limbense (Rathbun, 1914), P. palauense, Parasesarma panguaranense (Rathbun, 1914) and Parasesarma rutilimanum (Tweedie, 1936)], DNA extraction was not successful, mainly because of DNA degradation of the available material.

Fragments of four genes, namely the mitochondrial protein-coding gene cytochrome $c$ oxidase subunit I (COX1), the mitochondrial gene encoding the ribosomal RNA (rRNA) of the large ribosomal subunit (16S) and, for a subset of specimens, the nuclear protein-coding gene sodium-potassium ATPase alpha-subunit ( $\mathrm{NaK}$ ) and the nuclear gene encoding the rRNA of the large ribosomal subunit (28S), were amplified. For most of the examined species, DNA sequences of at least one genetic marker were used in the analyses (Table 2; Figs 2-4).

Polymerase chain reactions (PCRs) were performed using $1 \mathrm{X}$ reaction buffer, $250 \mu \mathrm{m}$ dNTPs, $2 \mathrm{mM} \mathrm{MgCl}_{2}$, $0.5 \mu \mathrm{M}$ of each primer and 0.5 unit Go Taq polymerase (or U Taq for the few cases in which REDiant $2 \mathrm{X}$ PCR Master Mix, $1^{\text {st }}$ BASE, Singapore was used), with the following profiles: initial denaturation step for $4 \mathrm{~min}$ at $94^{\circ} \mathrm{C} ; 40$ cycles with $45 \mathrm{~s}$ at $95{ }^{\circ} \mathrm{C}$ for denaturing, $60 \mathrm{~s}$ at $48{ }^{\circ} \mathrm{C}(C O X 1,16 \mathrm{~S}$ and $28 \mathrm{~S})$ or 58 ${ }^{\circ} \mathrm{C}(\mathrm{NaK})$ for annealing, $60 \mathrm{~s}$ at $72{ }^{\circ} \mathrm{C}$ for extension and 5 min at $72{ }^{\circ} \mathrm{C}$ as a final extension step. To amplify a segment of $\sim 604 \mathrm{bp}$ of the $N a K$ gene (including the primer regions), the primers $\mathrm{NaK}$ for-b2 (forward) and NaK rev3 (reverse) were used. For the $28 \mathrm{~S}$ gene, the primer combination 28L4 (forward) and $28 \mathrm{H} 4$ (reverse) was used to amplify a segment of $\sim 690 \mathrm{bp}$; if this combination did not work, the new primer $28 \mathrm{H} 6$ was used as a reverse primer to amplify a shorter 


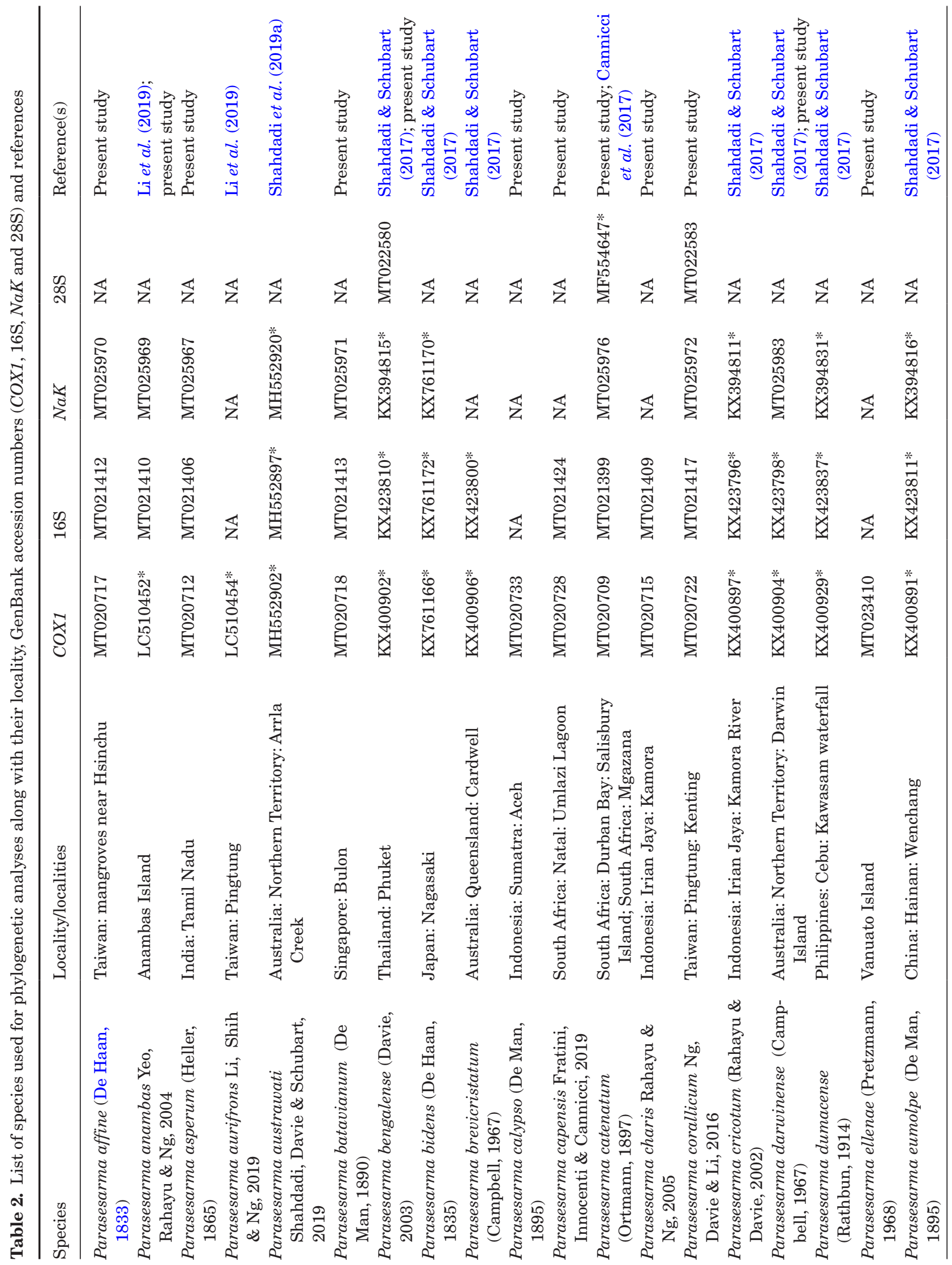




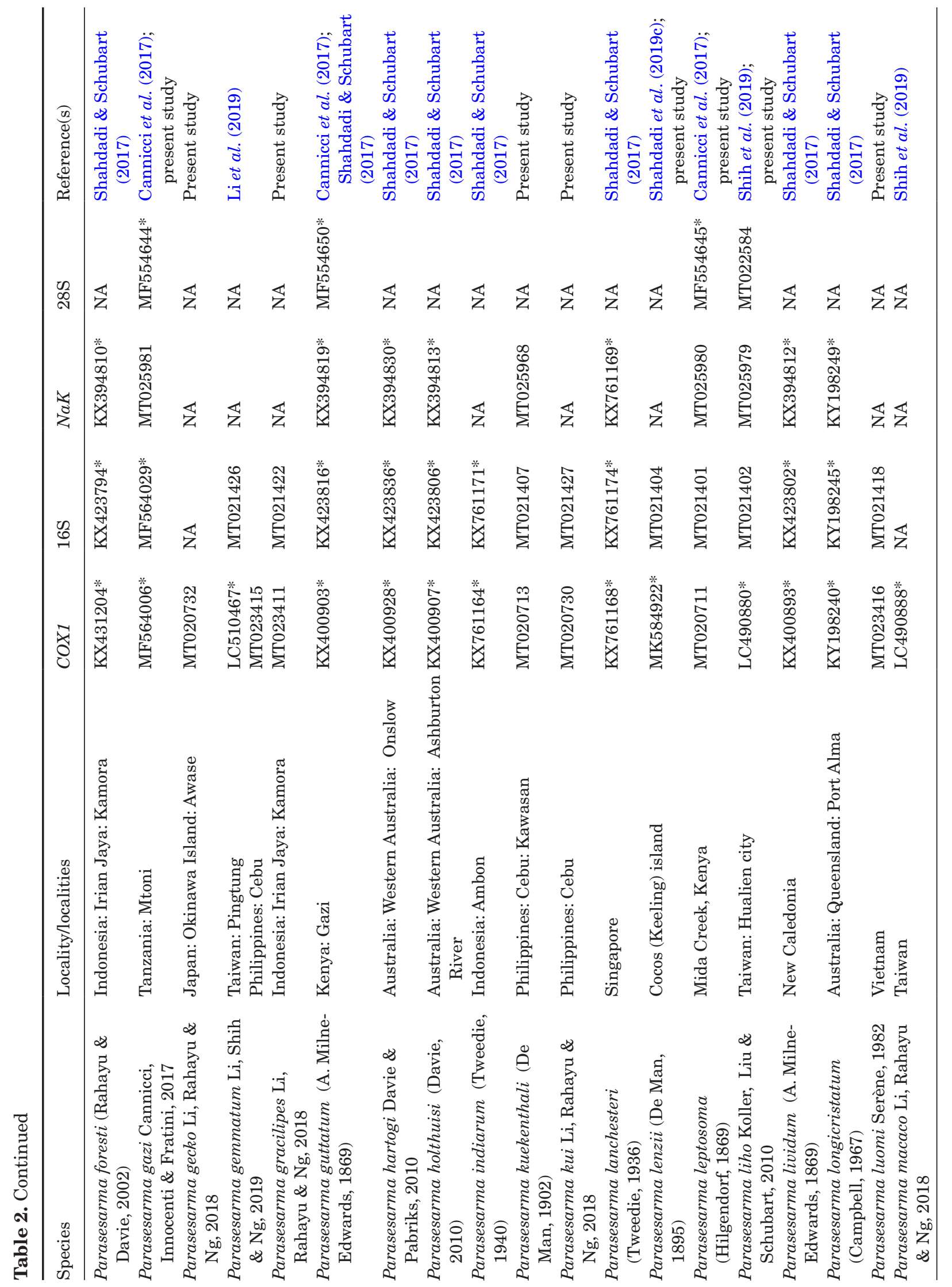




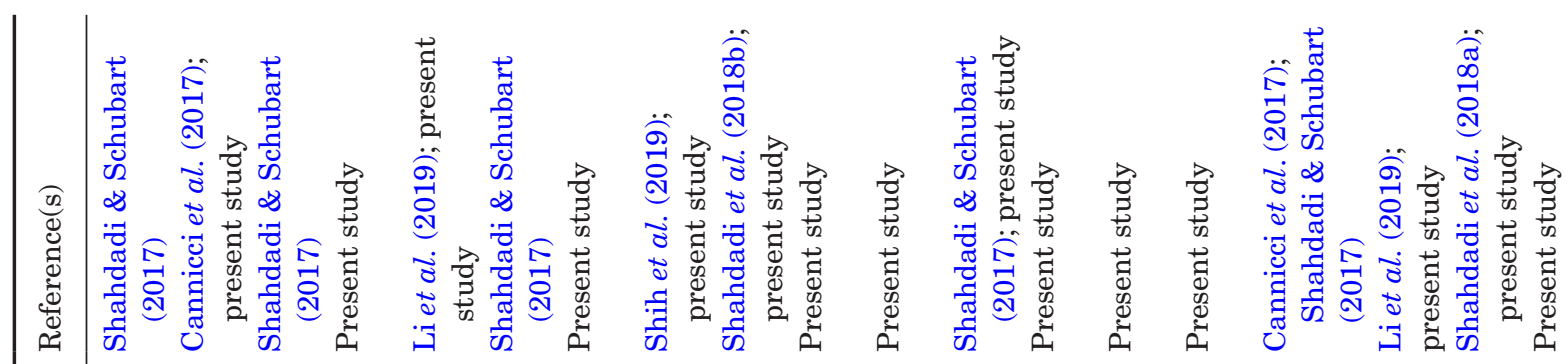

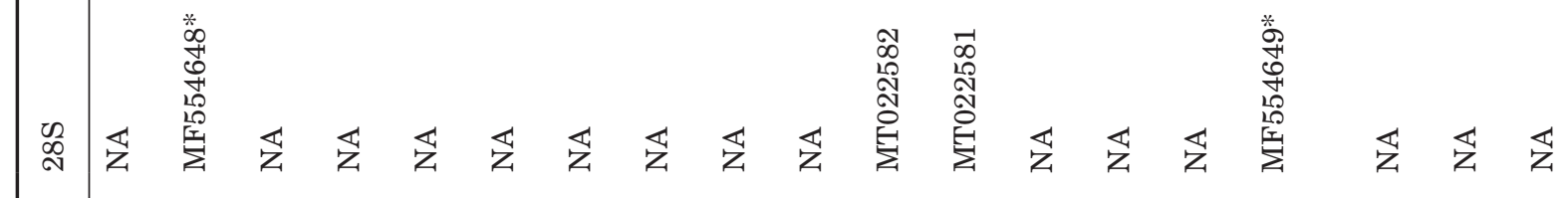

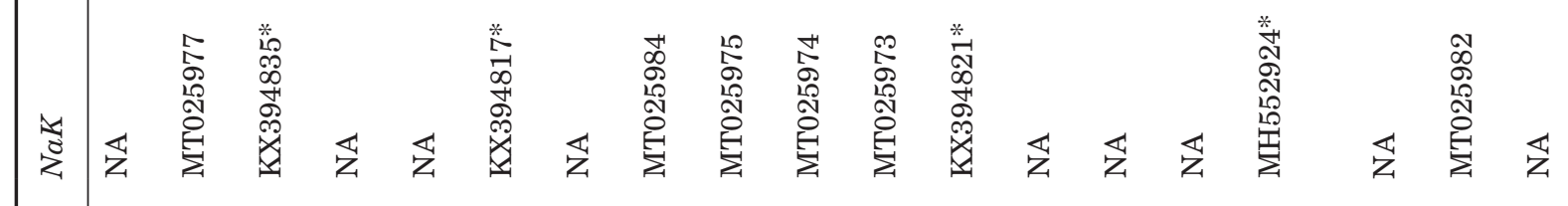

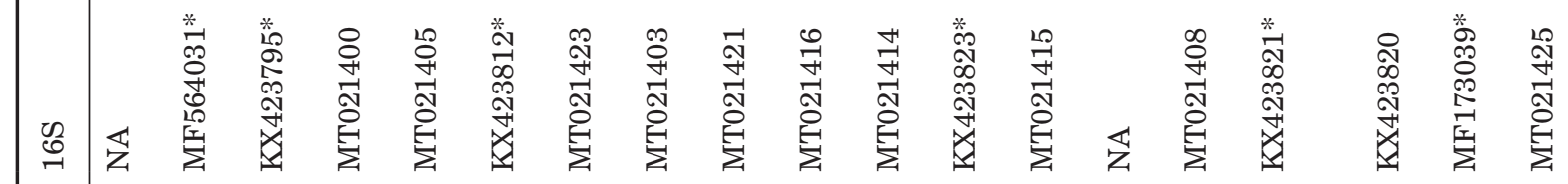

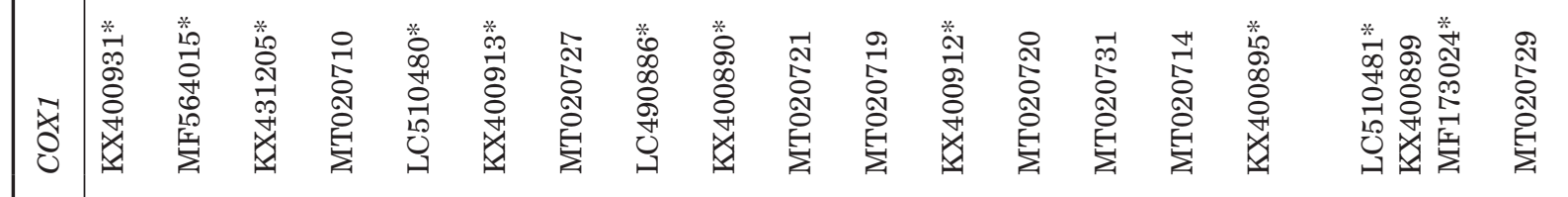

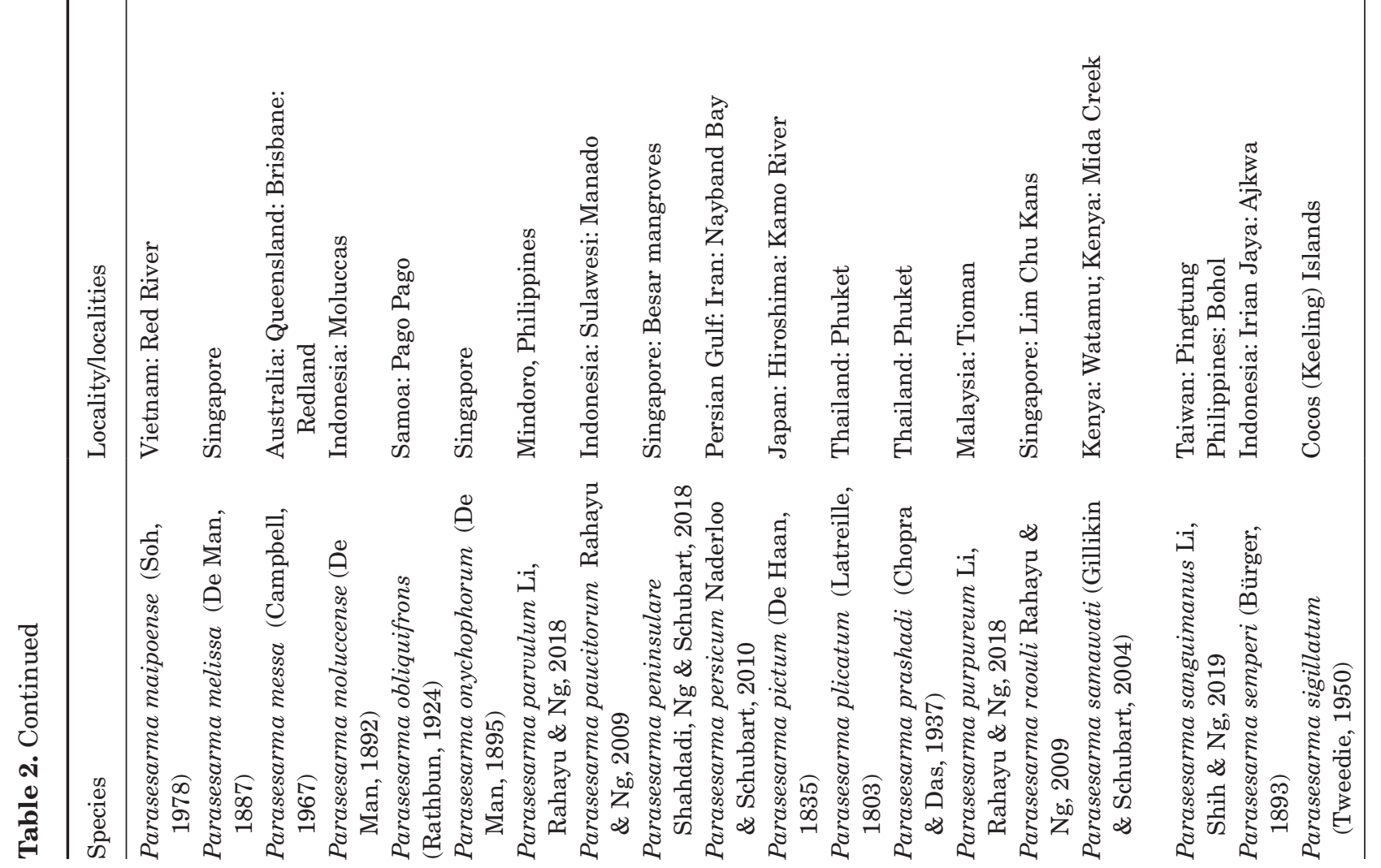




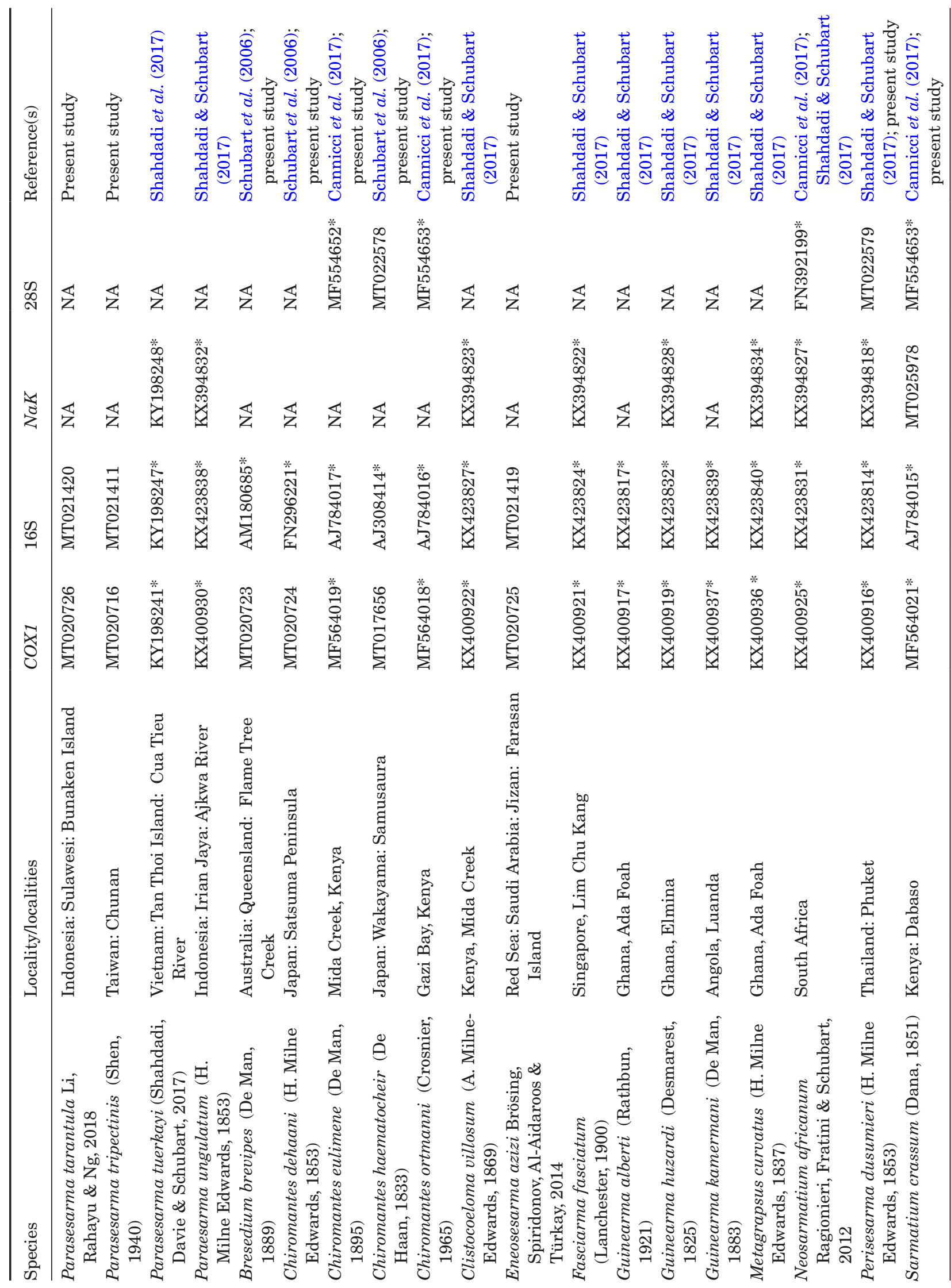




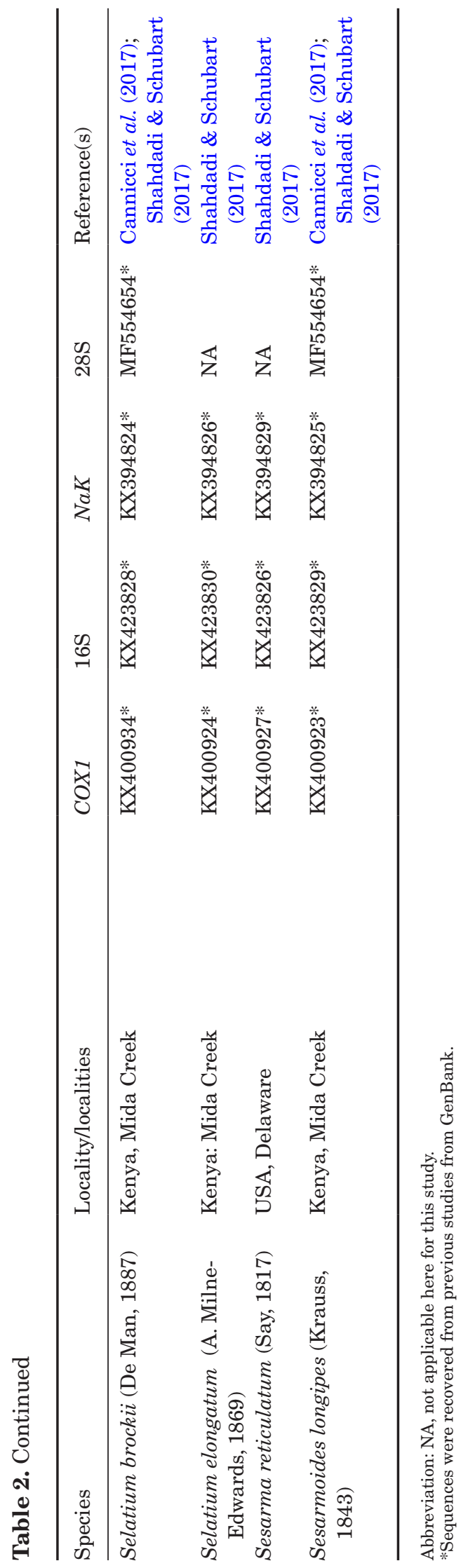

segment ( $577 \mathrm{bp})$. Different primer combinations had to be used to amplify fragments of varying lengths of the mitochondrial genes COX1 and 16S, owing to the variation in quality of the extracted DNA. The primer combination COL6-COH6 (in a few cases, LCO1490-HCO2198) was used to amplify a segment of $709 \mathrm{bp}$ of COX1 (including primer regions). For old museum specimens with strong DNA degradation and fragmentation, sequencing of two overlapping shorter fragments $(\sim 350-400 \mathrm{bp})$ allowed amplification of the same segment using the taxon-specific primer combinations COL6-COH7P and COL7-COH6. The primer combination 16L2-16H11 was used to amplify a fragment of the $16 \mathrm{~S}$ gene with a length of $~ 585-600$ bp (for detailed primer information, see Table 3 ).

The PCR products were outsourced for sequencing to Macrogen Europe or $1^{\text {st }}$ BASE Singapore. Sequences were proofread using Chromas Lite (v.2.1.1; Technelysium Pty Ltd, South Brisbane, Queensland, Australia). Primer regions were removed and the remaining sequences aligned with ClustalW (Thompson et al., 1994) implemented in BioEdit v.7.0.5 (Hall, 1999). New sequences were submitted to the National Center for Biotechnology Information (NCBI) and are available from GenBank under the accession numbers shown in Table 2. Homologous sequences from previous studies were also recovered from GenBank and included in further statistical analyses (Table 2).

The best evolutionary models describing our various datasets were determined with the aid of jModelTest (v.2.1.4; Darriba et al., 2012) and selected with the Akaike information criterion (AIC; Posada \& Buckley, 2004). Three alignments, one for the concatenated dataset of the two mitochondrial genes and two from the individual nuclear genes, were converted to Nexus files with FaBox (Villesen, 2007) as input files for subsequent phylogenetic analyses. The data of the concatenated alignment were partitioned by gene, because the markers have different mutation characteristics. Pairwise genetic distances for the COX1 gene [Kimura two-parameter model (K2P)] were calculated with the software MEGA v.5.2.2 (Tamura et $a l ., 2011$ ).

Two methods of phylogenetic inference were applied to our data: maximum likelihood (ML) using the software raxmlGUI (v.1.3; Silvestro \& Michalak, 2012) and Bayesian inference (BI) as implemented in MrBayes (v.3.2; Huelsenbeck \& Ronquist, 2001). Maximum likelihood trees were obtained for each alignment with 1000 bootstrap pseudoreplicates. For the $\mathrm{BI}$ analysis, we used two million generations with four chains (one heated) and a sample frequency of one tree per 1000 generations.

To clarify the phylogenetic positions of representatives of Parasesarma within the Sesarmidae, species of other sesarmid genera were 


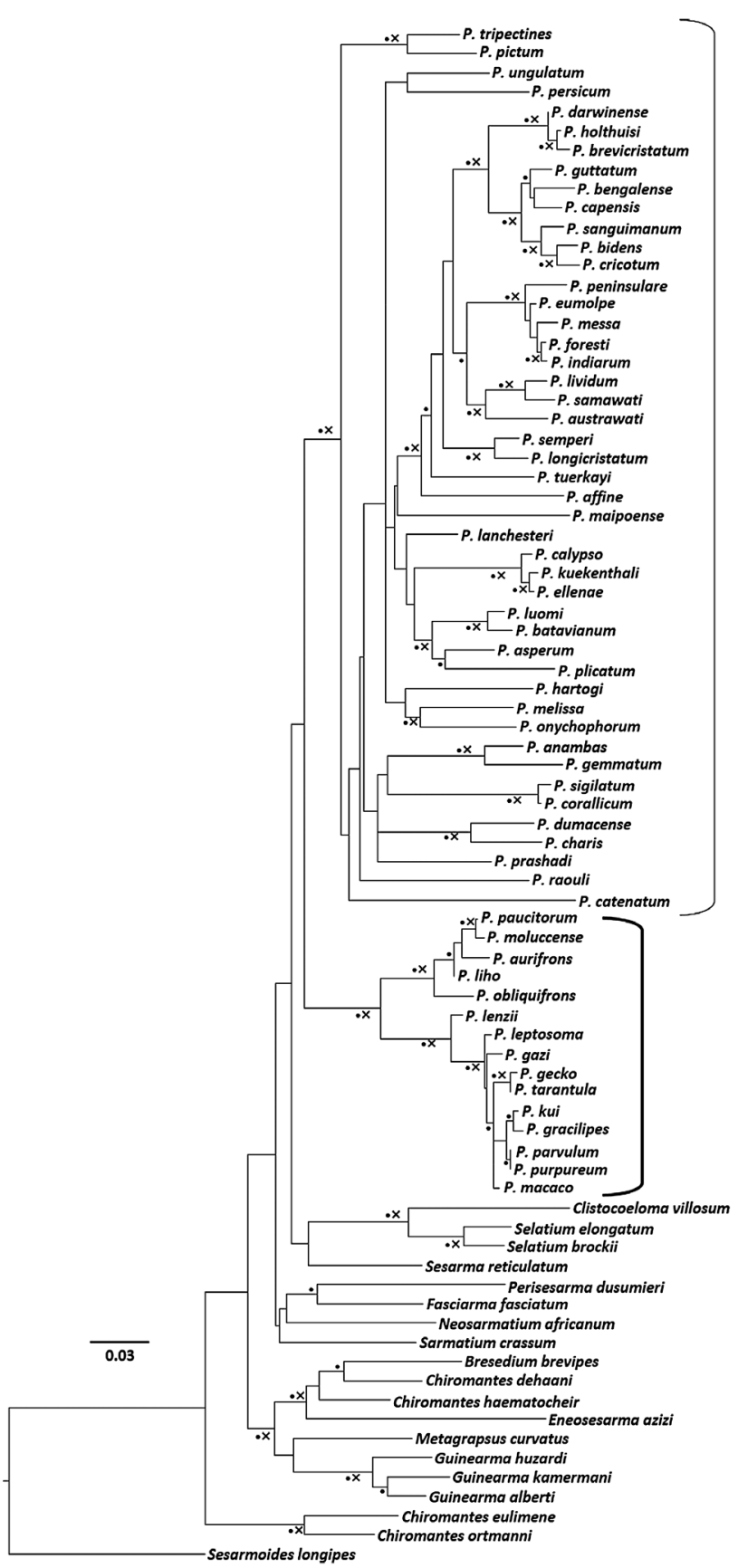

Figure 2. Maximum likelihood (ML) consensus tree topology inferred from the concatenated dataset (COX1, 16S) of selected sesarmid crabs (focusing on Parasesarma). - sign refers to bootstrap values $>50 \%$ in $\mathrm{ML}$; $\times$ sign refers to posterior probabilities $>0.95$ in Bayesian inference. Sesarmoides longipes was used as the outgroup. Thin bracket refers to the Parasesarma plicatum group; thick bracket refers to the clade of the Parasesarma leptosoma group.

included in the analyses (Table 1) as representatives of different phylogenetic clades (see Schubart et al., 2006; Shahdadi \& Schubart, 2017). Sesarmoides longipes (Krauss, 1843) was used as the outgroup in tree constructions according to its basal phylogenetic position within the family, as recovered in previous studies (see Schubart et al., 2006).

\section{RESULTS}

\section{MOLECULAR ANALYSIS}

After removal of the primer sequences and adjacent regions, the cropped alignments of $\mathrm{NaK}, 28 \mathrm{~S}, 16 \mathrm{~S}$ and $C O X 1$ consisted of 540,578, 553 and $645 \mathrm{bp}$, respectively, and the concatenated alignment of the two mitochondrial genes consisted of $1198 \mathrm{bp}$. The alignments of the protein-coding genes did not reveal any stop codons or indels, which would have indicated the presence of pseudogenes. The best evolutionary model for genetic analyses obtained with jModelTest (Guindon \& Gascuel, 2003) for the 28S, NaK and COX1 $+16 \mathrm{~S}$ alignments was the general time reversible plus gamma (GTR+G; Rodríguez et al., 1990). Six phylogenetic trees were obtained by applying ML and BI analyses to each of the three alignments. Given that the trees from ML and BI analyses had similar topologies, here we present only the ML trees, but including confidence values of both analyses (bootstrap values for ML and posterior probabilities for BI; Figs 2-4).

In all phylogenetic trees, species of Parasesarma are split into two distinct clades: a main clade of Parasesarma containing most species of the genus, including the type species [here referred to as Parasesarma plicatum (Latreille, 1803) group and shown in thin brackets in Figs 2-4], and a second clade of Parasesarma, including P. leptosoma and 14 related species ( $P$. leptosoma group; thick brackets in Figs 2-4). The two reciprocally monophyletic groups are highly supported in most cases by both analyses, with bootstrap values $>50$ and posterior probabilities $>0.95$ (Figs 2-4). Members of the P. leptosoma group are also clearly separated from all other examined genera of Sesarmidae (Figs 2-4).

The tree constructed from the two mitochondrial genes includes more species than the other two trees. It provides evidence that the clade of the P. leptosoma group consists of two distinct and well-supported subclades (Fig. 2). In the subclade composed of $P$. aurifrons, Parasesarma liho Koller, Liu \& Schubart, 2010, Parasesarma moluccense (De Man, 1892), Parasesarma paucitorum Rahayu \& Ng, 2009 and Parasesarma obliquifrons (Rathbun, 1924), the last species is isolated from the others, of which $P$. moluccense and $P$. paucitorum show a tight association. The second subclade includes Parasesarma lenzii (De Man, 1895) (holding a basal position) and nine closely related species. These nine species (i.e. P. leptosoma, 


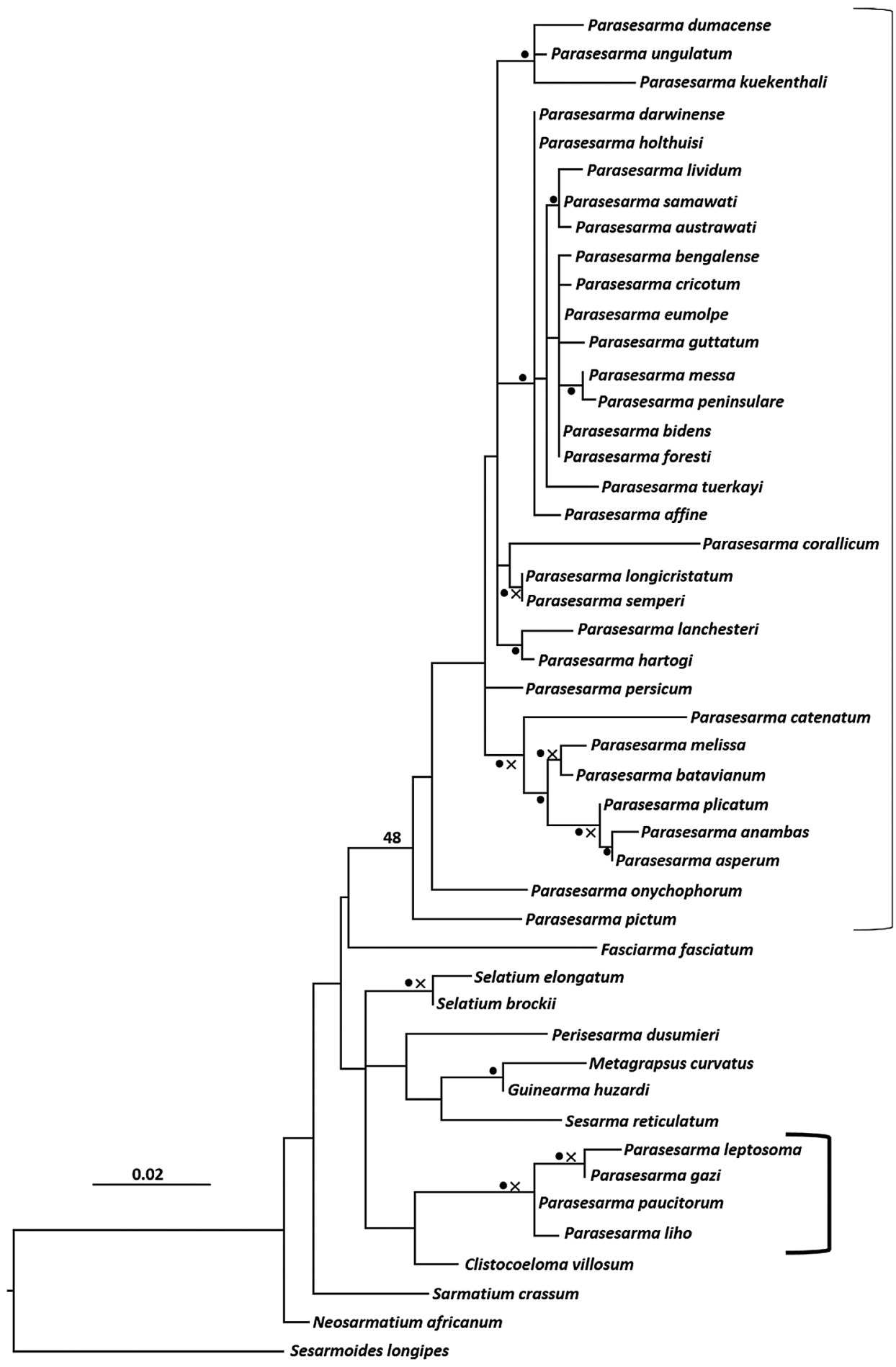

Figure 3. Maximum likelihood (ML) consensus tree topology inferred from the $N a K$ gene of selected sesarmid crabs (focusing on Parasesarma). $\bullet$ sign refers to bootstrap values $>50 \%$ in ML; $\times$ sign refers to posterior probabilities $>0.95$ in Bayesian inference. Sesarmoides longipes was used as the outgroup. Thin bracket refers to the Parasesarma plicatum group; thick bracket refers to the clade of the Parasesarma leptosoma group. 


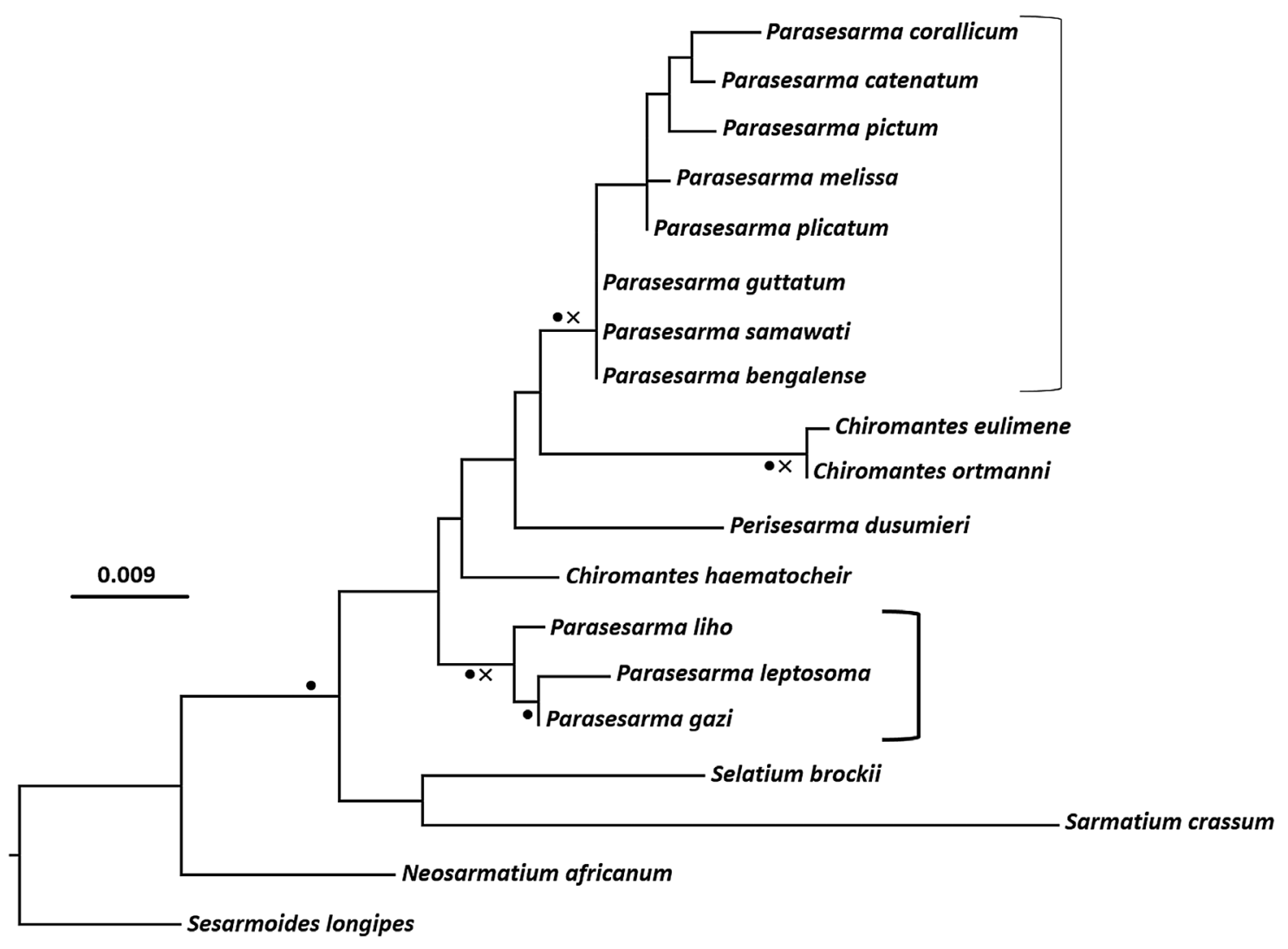

Figure 4. Maximum likelihood (ML) consensus tree topology inferred from $28 \mathrm{~S}$ gene of selected sesarmid crabs (focusing on Parasesarma). $\bullet$ sign refers to bootstrap values $>50 \%$ in $\mathrm{ML}$; $\times$ sign refers to posterior probabilities $>0.95$ in Bayesian inference. Sesarmoides longipes was used as the outgroup. Thin bracket refers to the Parasesarma plicatum group; thick bracket refers to the clade of the Parasesarma leptosoma group.

P. gazi, Parasesarma macaco Li, Rahayu \& Ng, 2018, Parasesarma parvulum Li, Rahayu \& Ng, 2018, Parasesarma purpureum Li, Rahayu \& Ng, 2018, Parasesarma kui Li, Rahayu \& Ng, 2018, Parasesarma gracilipes Li, Rahayu \& Ng, 2018, Parasesarma gecko Li, Rahayu \& Ng, 2018 and Parasesarma tarantula $\mathrm{Li}$, Rahayu \& Ng, 2018) show low genetic divergences in the mitochondrial tree (Fig. 2). Among them, the pairs formed by $P$. gecko with P. tarantula and P. kui with $P$. gracilipes are closely associated. Parasesarma purpureum and P. parvulum share the same haplotype in the COX1 gene.

In the clade of the $P$. plicatum group, there are also several supported and stable subclades. The subclade of P. tripectinis-Parasesarma pictum (De Haan, 1833) holds a basal position within this group. The three species Parasesarma calypso (De Haan, 1895), Parasesarma kuekenthali (De Man, 1902) and Parasesarma ellenae (Pretzmann, 1968) show a tight association. There are several other highly supported species pairs [e.g. Parasesarma anambas Yeo, Rahayu \& P.K. L.Ng, 2004-Parasesarma gemmatum Li, Shih \&Ng, 2019; Parasesarma luomi Serène, 1982-Parasesarma batavianum (De Man, 1890); Parasesarma dumacense (Rathbun, 1914)-Parasesarma charis Rahayu \& Ng, 2005; and Parasesarma corallicum Ng, Davie \& Li, 2016-Parasesarma sigillatum (Tweedie, 1950)]. The largest stable and supported cluster comprises 21 species, with Parasesarma affine (De Haan, 1837) and Parasesarma tuerkayi Shahdadi, Davie \& Schubart, 2017 holding a basal position. In this group, there are several solid groups [i.e. Parasesarma lividum (A. Milne-Edwards, 1869) group, Parasesarma indiarum (Tweedie, 1940) group, Parasesarma darwinense (Campbell, 1967) group, Parasesarma bidens (De Haan, 1833) group and Parasesarma semperi (Bürger, 1893) group], but the phylogenetic relationships among several other species of Parasesarma are otherwise not fully resolved, as shown by the occurrence of several clades with low support values.

The subdivision of the genus Parasesarma into two monophyletic clades is also confirmed by the nuclear markers, although the phylogenies within each clade are less resolved (Figs 3, 4). Parasesarma leptosoma and $P$. gazi are stably associated in both trees (Figs 3,4). However, in the NaK tree some supported clusters can be 
Table 3. Primers used in the present study with the corresponding DNA sequences $\left(5^{\prime}-3^{\prime}\right)$ and references

\begin{tabular}{|c|c|c|c|}
\hline Gene & Primer & Sequences & References \\
\hline \multirow[t]{6}{*}{$C O X 1$} & COL6 & TYTCHACAAAYCATAAAGAYATYGG & Schubart (2009) \\
\hline & LCO1490 & GGTCAACAAATCATAAAGATATTGG & Folmer et al. (1994) \\
\hline & COL7P & GGTGTKGGMACMGGATGAACTGT & Shahdadi et al. (2018a) \\
\hline & $\mathrm{COH} 7 \mathrm{P}$ & GRAGAGAAAAAATACCTA & Shahdadi \& Schubart (2017) \\
\hline & $\mathrm{COH} 6$ & TADACTTCDGGRTGDCCAAARAAYCA & Schubart \& Huber (2006) \\
\hline & HCO2198 & TAAACTTCAGGGTGACCAAAAAATCA & Folmer et al. (1994) \\
\hline \multirow[t]{2}{*}{$16 \mathrm{~S}$} & $16 \mathrm{~L} 2$ & TGCCTGTTTATCAAAAACAT & Schubart et al. (2002) \\
\hline & $16 \mathrm{H} 11$ & AGATAGAAACCRACCTGG & Schubart (2009) \\
\hline \multirow[t]{2}{*}{$N a K$} & NaK for-b2 & ATGACAGTCGCYCAYATGTGGTT & Modified from NaK for-b (from Tsang et al., 2008) \\
\hline & NaK rev3 & GGAGGRTCAATCATRGACAT & Tsang et al. (2014) \\
\hline \multirow[t]{3}{*}{$28 \mathrm{~S}$} & $28 \mathrm{~L} 4$ & TATTTCCCCTCGTGATGTAGGTC & Ragionieri et al. (2009) \\
\hline & $28 \mathrm{H} 6$ & AGCARAGCCGGCGAGGCCAACA & New \\
\hline & $28 \mathrm{H} 4$ & ACTCCGGACAGAGCAGGAT & Ragionieri et al. (2009) \\
\hline
\end{tabular}

recognized in the P. plicatum clade (Fig. 3). For instance, a cluster of six species holds a basal position, and the association of Parasesarma asperum (Heller, 1865), $P$. anambas, $P$. plicatum, $P$. batavianum and Parasesarma melissa (De Man, 1888) together with Parasesarma catenatum (Ortmann, 1897) is highly supported. This cluster also includes two smaller groups with high support, i.e. P. melissa + P. batavianum and P. plicatum $+P$. anambas $+P$. asperum (Fig. 3 ). In the P. plicatum group, the same cluster of 15 species as found in the mitochondrial tree forms the largest supported cluster in the NaK tree, with $P$. affine holding a basal position (Fig. 3).

\section{MORPHOLOGICAL ANALYSES}

Morphological examinations of the chelae show that adult males in all described species of Parasesarma have two or three oblique pectinated crests on the upper surface of the palm and a series of tubercles on the dorsal face of the dactyli (Fig. 5). The patterns of the tuberculation, i.e. the numbers and shapes of these tubercles, are some of the most variable features among species of Parasesarma (Fig. 5). However, careful examinations of the pectinated crests of the palms show that members of the P. leptosoma group have a slightly different palm crest and dactylar tuberculation pattern in comparison to species of the P. plicatum group. In species of the P. leptosoma group, the pectinated crests on the upper palm surface are oblique, but more longitudinal, with each one extending into a line of coarse granules on the outer side (Fig. $5 \mathrm{~F}-\mathrm{J})$. The innermost and proximal pectinated crest and its extended granule line create a ridge and divide the upper surface of the palm into two separate parts, an outer and an inner part (Fig. 6D-F). In the case of the dactyli, the proximal tubercles are positioned towards the mid-dactylar dorsal face, and a virtual line of dactylar tubercles would extend proximally to the outer granules of the distal pectinated crest (Fig. 7B). In members of the $P$. plicatum group, the pectinated crests have a more transverse orientation on the upper palm surface, which is undivided despite the presence of some granules (Figs 5A-E, 6A-C). The proximal dactylar tubercles are found on the inner side of the dactylar dorsal face, and the virtual line of dactylar tubercles would extend proximally to the inner teeth of the distal pectinated crest (Fig. 7A).

The two groups of Parasesarma also differ in eye morphology (Fig. 8). The eyestalk in members of the P. leptosoma group is relatively shorter than wide (in dorsal view, the ratio of eyestalk length/width ranges from 0.74 to 0.98 ; Fig. $8 \mathrm{H}-\mathrm{N}$ ), whereas in members of the P. plicatum group the eyestalk is longer than wide (the ratio of eyestalk length/width ranges from 1.08 to 1.71; Figs 8A-G, 9A; Table 1). Consequently, species of the P. leptosoma group (Fig. $8 \mathrm{H}-\mathrm{N}$ ) have proportionally deeper orbits compared with members of the P. plicatum group (Fig. 8A-G).

Species of the P. leptosoma group have proportionally long ambulatory legs: $\mathrm{P} 4$ (ischium-dactylus)/cw values range from 1.81 (in $P$. lenzii) to 2.20 (in P. gecko). In contrast, there is a wider range concerning $\mathrm{P} 4$ (ischium-dactylus)/cw values among species of the $P$. plicatum group, i.e. from 1.49 (in P. carolinense) to 1.96 (in P. pictum) (Fig. 9B; Table 1).

Morphological analyses of G1 indicate a high variability within both groups, each one containing species with moderately different G1 (Fig. 10), but generally sharing a similar shape overall. 

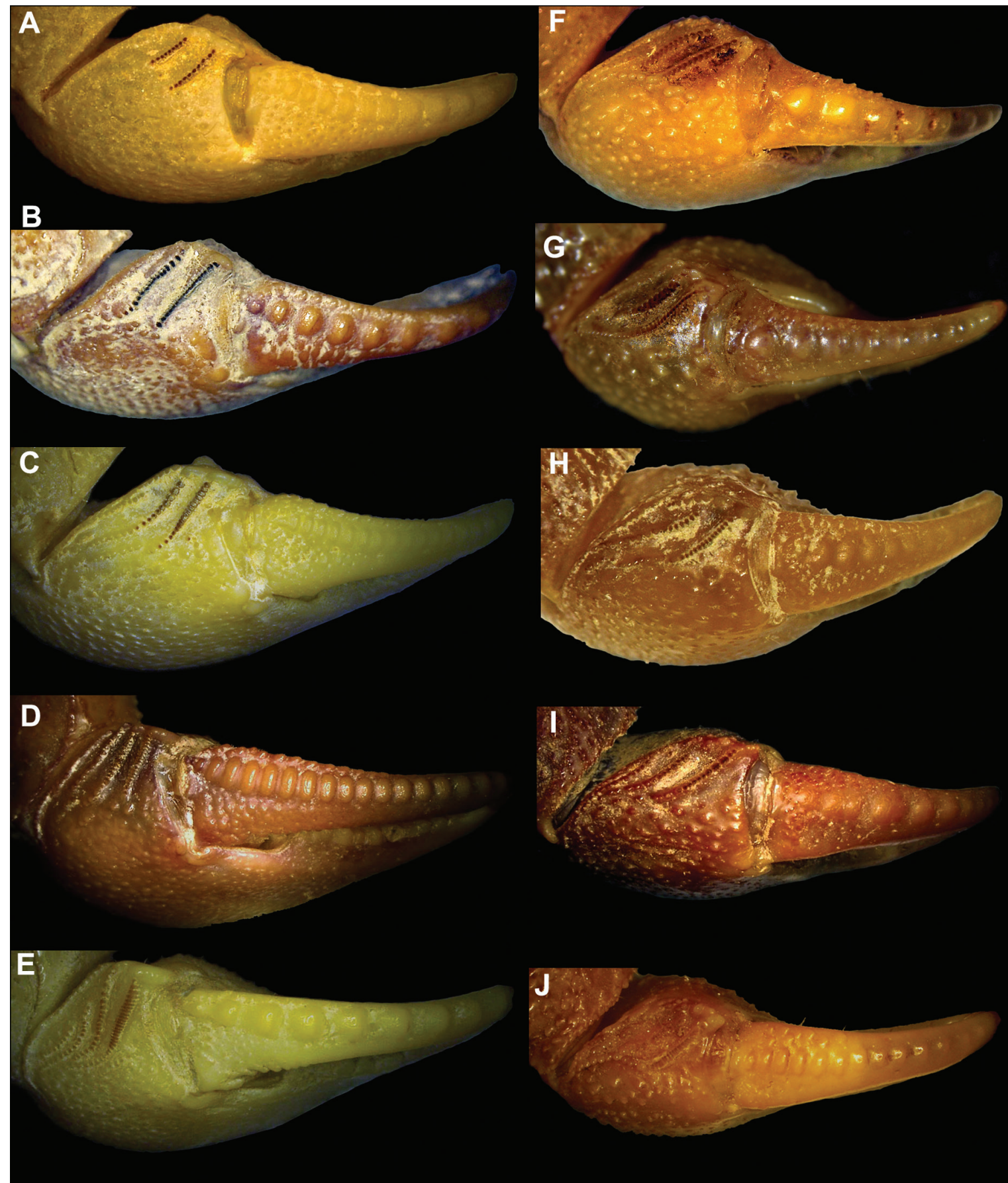

Figure 5. Dorsal view of male right chelae (palm pectinated crests and dactylar tubercles) in selected species of Parasesarma; A-E, members of the Parasesarma plicatum group; F-J, members of Parasesarma leptosoma group. A, P. plicatum (17.6 mm $\times 14.1 \mathrm{~mm}$; NHMW 1637), Sri Lanka. B, Parasesarma affine $(24.0 \mathrm{~mm} \times 19.4 \mathrm{~mm}$; ZSM-A20171197), Hong Kong: Mai Po mangrove. C, Parasesarma asperum (18.7 mm × 15.5 mm; NHMW 10408), Nicobar Islands: Novara. D, Parasesarma bengalense $(19.4 \mathrm{~mm} \times 16.4 \mathrm{~mm}$; SMF 49919), Thailand: Phuket. E, Parasesarma longicristatum $(18.5 \mathrm{~mm} \times$ 14.9 mm; QM-W2464), Australia: Queensland: Port Alma. F, P. leptosoma (17.7 mm × 16.0 mm; MZUF 4977), Kenya, Mida Creek. G, Parasesarma purpureum (13.0 mm $\times 11.5 \mathrm{~mm}$; ZRC 1017.1240), Malaysia: Tioman. H, Parasesarma liho (13.0 mm $\times 11.6$ mm; ZRC 2013 1757), Taiwan: Pingtung Manchow. I, Parasesarma paucitorum (19.9 mm × 18.8 mm; MZB.cru.2243), Indonesia: Sulawesi: Manado. J, Parasesarma gazi (15.5 mm × $13.1 \mathrm{~mm}$; MZUF 3671), Kenya: Gazi Bay. 

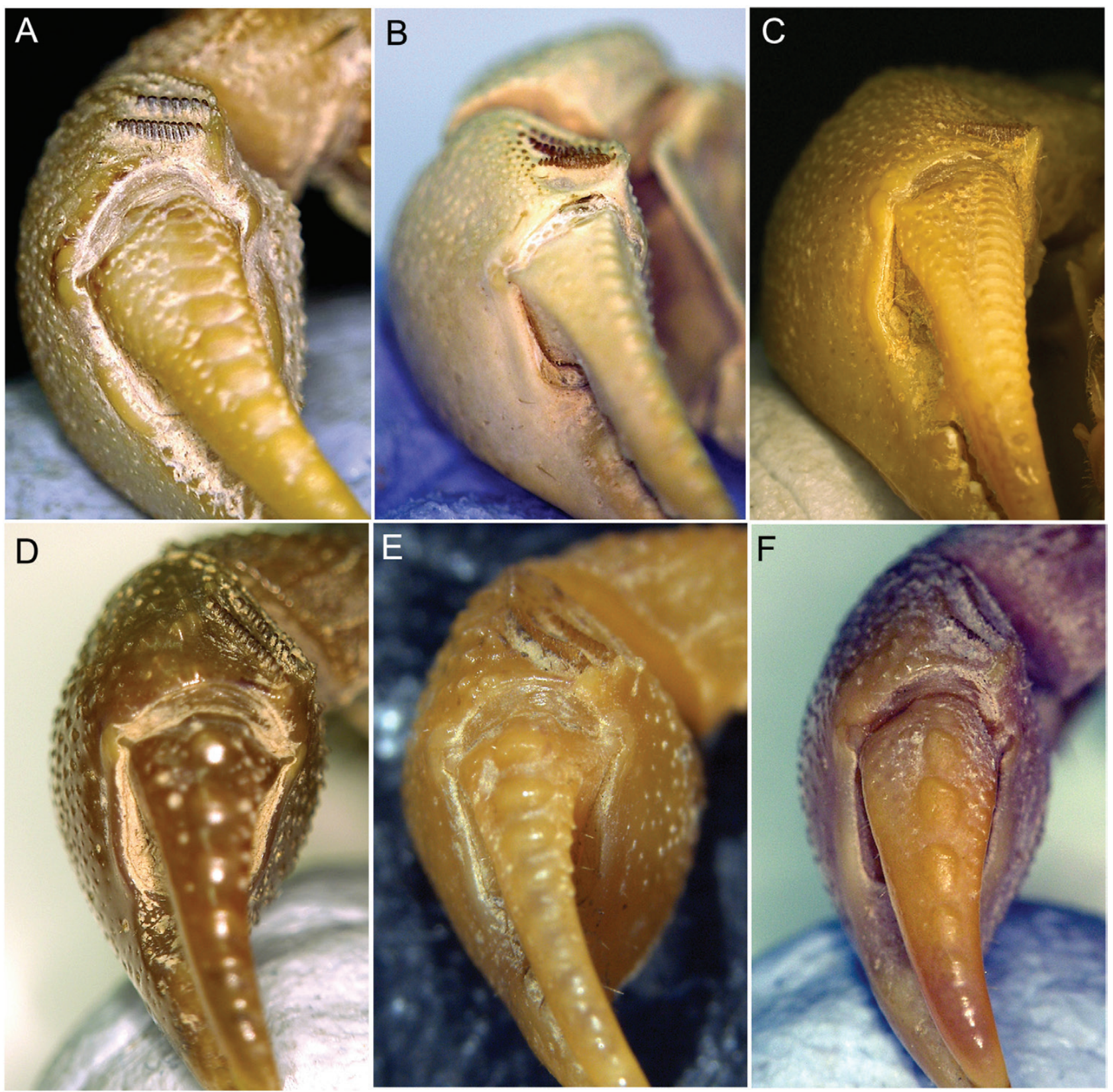

Figure 6. Dorsal view of male right chelae (palm pectinated crests and dactylar tubercles) in selected species of Parasesarma; A-C, members of Parasesarma plicatum group; D-F, members of Parasesarma leptosoma group. A, P. plicatum (21.7 mm $\times$ 17.4 mm; SMF 49926), Sri Lanka. B, Parasesarma lepidum (10.4 mm × 7.8 mm; ZRC1964.9.3.466), Malaysia: Labuan. C, Parasesarma batavianum (15.7 mm × $13.9 \mathrm{~mm}$; RMNH.CRUS.D1201), Indonesia: Java: Batavia. D, P. leptosoma (19.0 mm $\times 17.5$ mm; MZUF 4978), Kenya: Mida Creek. E, Parasesarma kui (13.1 mm × $12.1 \mathrm{~mm}$; ZRC 2018.0792), Taiwan: Pingtung. F, Parasesarma moluccense (14.6 mm × $13.6 \mathrm{~mm}$; RMNH.CRUS.D102590), Indonesia: Flores.

\section{DISCUSSION}

The establishment of a phylogeny-based classification of all living organisms is a fundamental aim of systematics. Convergent evolution, phenotypic plasticity, cryptic taxa and morphological changes during the ontogeny of a single species are common factors that render this aim difficult through the history of systematics. Genetic approaches have been thus become an important tool in resolving phylogeny in different groups, including decapod Crustacea (Schubart, 2009). Thereby, mitochondrial and, increasingly, nuclear markers prove to be a helpful 


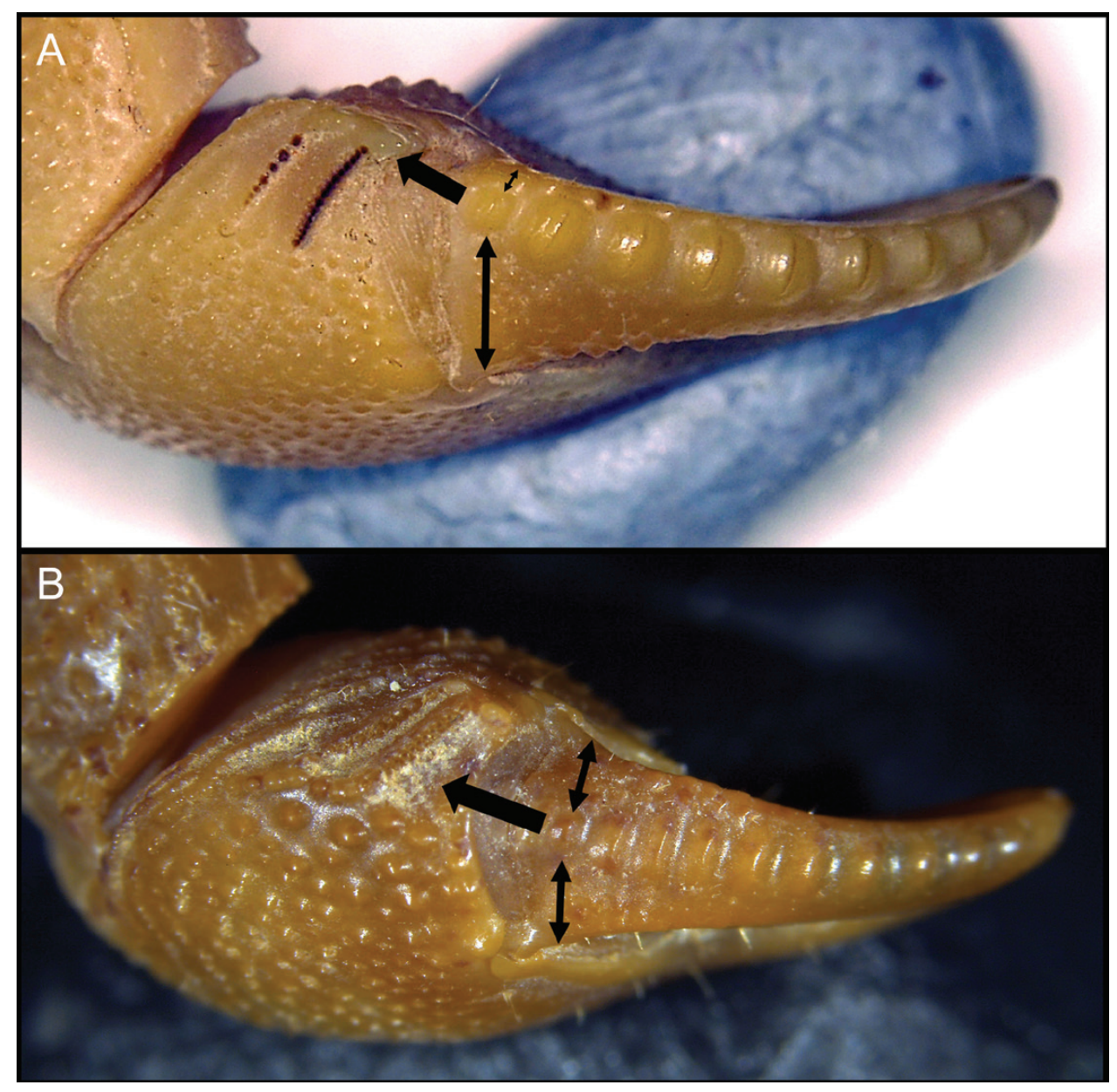

Figure 7. Morphological comparison of male palm pectinated crests and chelar dactylar tubercle of: A, Parasesarma brevicristatum (19.8 mm × 16.6 mm; QM-W2459), Australia: Queensland: Flying Fish Port (representative of Parasesarma plicatum group); B, Parasesarma gecko (15.8 mm $\times 14.3 \mathrm{~mm}$; RUMF-ZC-4710), Japan: Okinawa Island (representative of Parasesarma leptosoma clade). Thick and thin arrows indicate virtual line of dactylar tubercles and distance from inner and outer margins of dactylar margins, respectively.

source to evaluate the phylogenetic value of specific morphological characters (e.g. Shahdadi \& Schubart, 2017), especially in taxa, such as Parasesarma, that have a relatively small number of reliable morphological distinctions (Shahdadi \& Schubart, 2015).

The present molecular phylogenetic results (Figs 2-4) indicate heterogeneity and, according to nuclear markers, possible polyphyly in Parasesarma (as defined before the present study). They strongly support the separation and transfer of some of the constituent species to a new genus. After this rearrangement, according to the examined species, both resulting genera appear as monophyletic taxa. This agrees with previous evidence of the para- or polyphyly of Parasesarma, as already noted by Schubart et al. (2006) and Cannicci et al. (2017). Both clades of Parasesarma show a comb-like topology, with many closely related species pairs and complexes, suggesting recent and rapid radiations.

Species of Parasesarma s.l. share many morphological characters, the most conspicuous of which are the two transverse pectinated crests on the upper surface of the male chelar palms (Naderloo \& Schubart, 2010). Nevertheless, the present comparisons show that there are at least two different crest patterns among species of Parasesarma. Species of the P. leptosoma group show minor but consistent differences in these features compared with members of the P. plicatum group (see Results and Figs 5-7). Several sesarmid genera are known to have chitinous pectinated crest(s) on the upper surface of the chelar palm, combined with dactylar tuberculation (Serène \& Soh, 1970; Schubart et al., 2009; Davie, 2012). These 


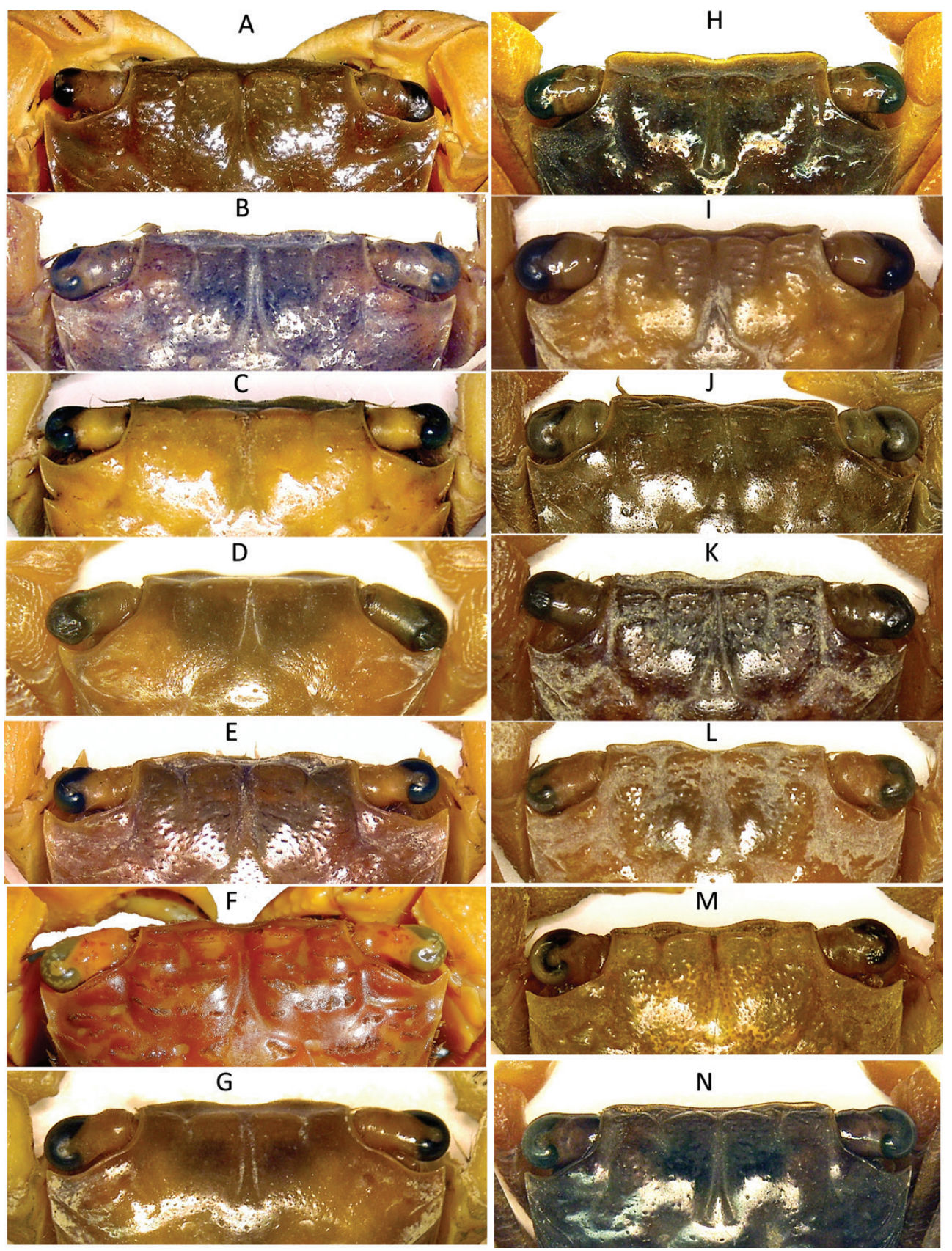

Figure 8. Dorsal view of carapace front, postorbital lobes, eyes and orbits in selected species of Parasesarma. A-G, members of Parasesarma plicatum group; H-N, members of Parasesarma leptosoma clade. A, P. plicatum, male (22.4 mm $\times 17.8 \mathrm{~mm}$; SMF 49918), Thailand: Phuket. B, Parasesarma asperum, male (16.0 mm × $13.0 \mathrm{~mm}$; ZRC 2001.0851), India: Tamil Nadu. C, Parasesarma brevicristatum, male (19.8 mm $\times 16.6$ mm; QM-W2459), Australia: Queensland: Flying Fish Port. D, Parasesarma charis, male $(8.9 \mathrm{~mm} \times 6.7 \mathrm{~mm}$; ZRC 2002.0594), Indonesia: Irian Jaya: Kamora. E, Parasesarma dumacense, male (18.7 mm $\times 15.7 \mathrm{~mm}$; ZRC 2008.0833), Philippines: Cebu. F, Parasesarma lanchesteri, male $(20.8 \mathrm{~mm} \times$ $16.2 \mathrm{~mm}$; NHM1947.11.18.24), Singapore: Jurong. G, Parasesarma tripectinis, male (9.9 mm $\times 8.0 \mathrm{~mm}$; ZSM-A20171189), Taiwan: Chunan Hsintong. H, P. leptosoma, male (17.7 mm $\times 16.1 \mathrm{~mm}$; MZUF 4977), Kenya: Mida Creek. I, Parasesarma jamelense, male (11.5 mm × $10.0 \mathrm{~mm}$; USNM 45917), Philippines: Luzon. J, Parasesarma lenzii, male $(11.8 \mathrm{~mm} \times 9.9$ mm; ZRC 2018.1373), Cocos (Keeling) Islands. K, Parasesarma liho, male (13.0 mm × 11.6 mm; ZRC 2013 1757), Taiwan: Pingtung Manchow. L, Parasesarma moluccense, male (14.6 mm × 13.6 mm; RMNH.CRUS.D102590), Indonesia: Flores. M, Parasesarma obliquifrons, male (12.7 mm × $11.1 \mathrm{~mm}$; USNM 45913), Samoa Island: Pago Pago. N, Parasesarma gazi, female (12.6 mm × $10.3 \mathrm{~mm}$; MZUF 3673), Kenya: Gazi Bay. 

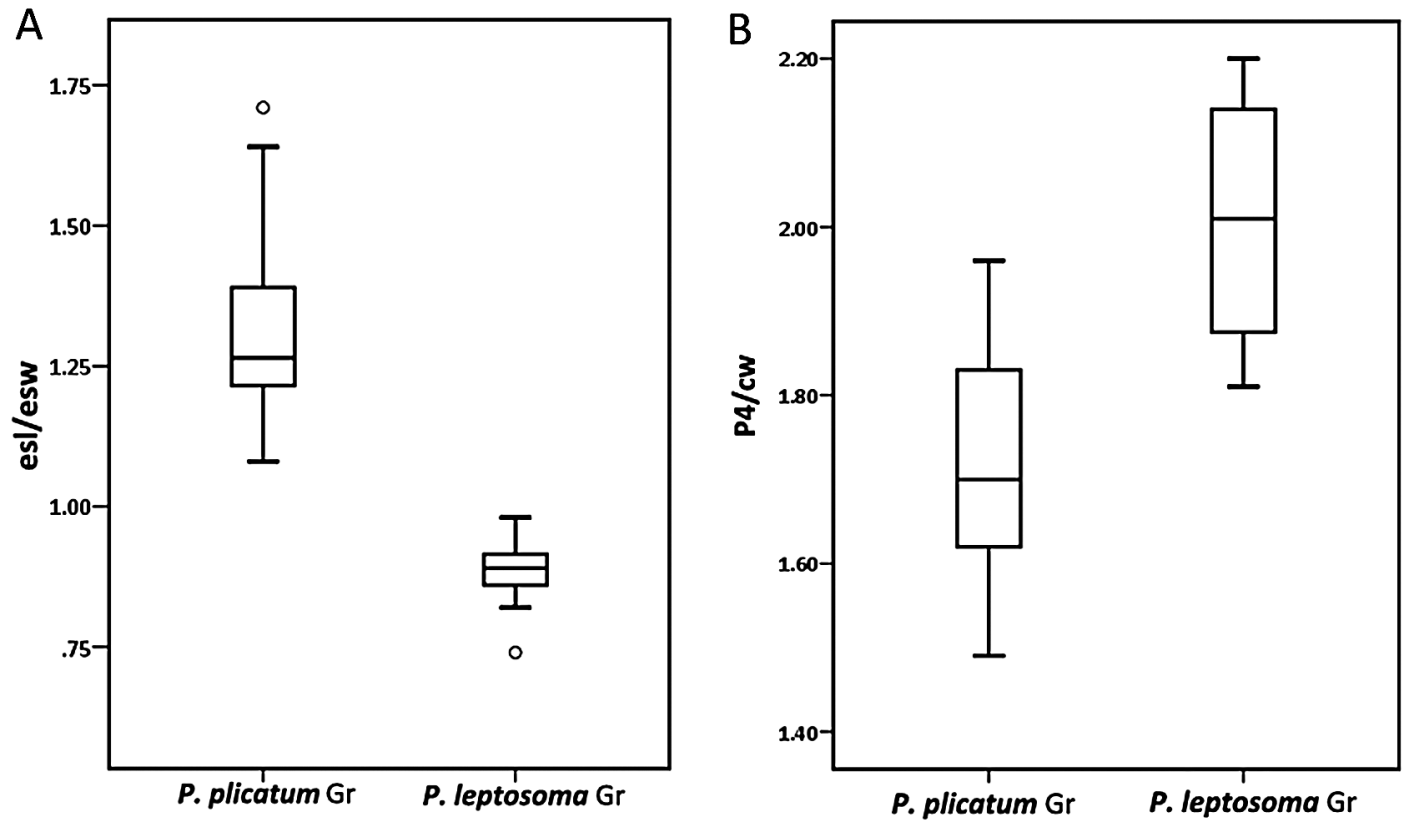

Figure 9. A, boxplots of morphometric comparisons between species of Parasesarma plicatum group $(N=52)$ and Parasesarma leptosoma clade $(N=16)$ : the ratio between eye stalk length (esl) and eye stalk width (esw). B, boxplots of morphometric comparisons between species of main Parasesarma clade $(N=37)$ and $P$. leptosoma $(N=16)$ : the ratio between length of pereiopod 4 (P4) and carapace width (cw).

structures are recognized as key features in inter- and intraspecific communication (Chen et al., 2014, 2017). Boon et al. (2009) described the mechanisms of the resulting stridulation (i.e. rubbing dactylar tubercles against pectinated crests of opposite chela) and showed that different types of tubercles result in different signals (Boon et al., 2009: figs 1-4). Species within a sesarmid genus generally differ in the number, pattern and type of the tuberculation, whereas the pectinated crests appear to be similar (e.g. Fig. 5). However, among sesarmid genera these crests may differ in orientation, pattern and type of chitinous teeth (e.g. Shahdadi \& Schubart, 2017: figs 3, 4). These authors also considered the similarity of these features as important phylogenetic indicators for close kinship. However, they also discussed how differences in these characters could also be a key reason for isolation in behaviour and communication (see also Shahdadi et $a l ., 2018 \mathrm{~b}$ ), with consequent reproductive isolation leading to different evolutionary lineages, as shown in the two cases of Perisesarma dusumieri (H. Milne Edwards, 1853) and Fasciarma fasciatum (Lanchester, 1900) by Shahdadi \& Schubart (2017).

Separation between sister species of Parasesarma has also been associated with allopatric speciation events, without evolution of strong morphological differences. Shahdadi et al. (2018a, 2019a) discussed how the genetic divergence between two northern Australian species of Parasesarma (i.e. P. semperi and Parasesarma austrawati Shahdadi, Davie \& Schubart, 2019) is a result of gene flow disjunction between Australia and other areas. Otherwise, these species are morphologically similar to their relatives [i.e. Parasesarma longicristatum (Campbell, 1967) and Parasesarma samawati (Gillikin \& Schubart, 2004), respectively]. In contrast, Parasesarma eumolpe (De Man, 1895) is genetically close to other related species of its group (e.g. Parasesarma peninsulare Shahdadi, $\mathrm{Ng} \&$ Schubart, 2018), but distinctly different from all other relatives in the morphology of chelar dactylar tubercles (Shahdadi et al., 2018b).

Within Parasesarma, a probable case of speciation attributable to an interspecific hybridization event was also reported for P. leptosoma and P. gazi (Cannicci et al., 2017), two species that live in sympatry in mangrove forests in Kenya and Tanzania. This was the first report of a hybridization event for sesarmid crabs in general.

Another possibly important feature for the taxonomy of these crabs is the morphology of G1 (Shahdadi \& Schubart, 2017; Li et al., 2018). Li et al. (2018) described seven new species of the long-legged Parasesarma with distinct morphological identities, especially regarding the morphology of G1 and chelar dactylar tubercles. However, in the present study these species show close genetic affinity in their mitochondrial DNA sequences. Our comparisons show that G1 morphology is a useful and diagnostic 


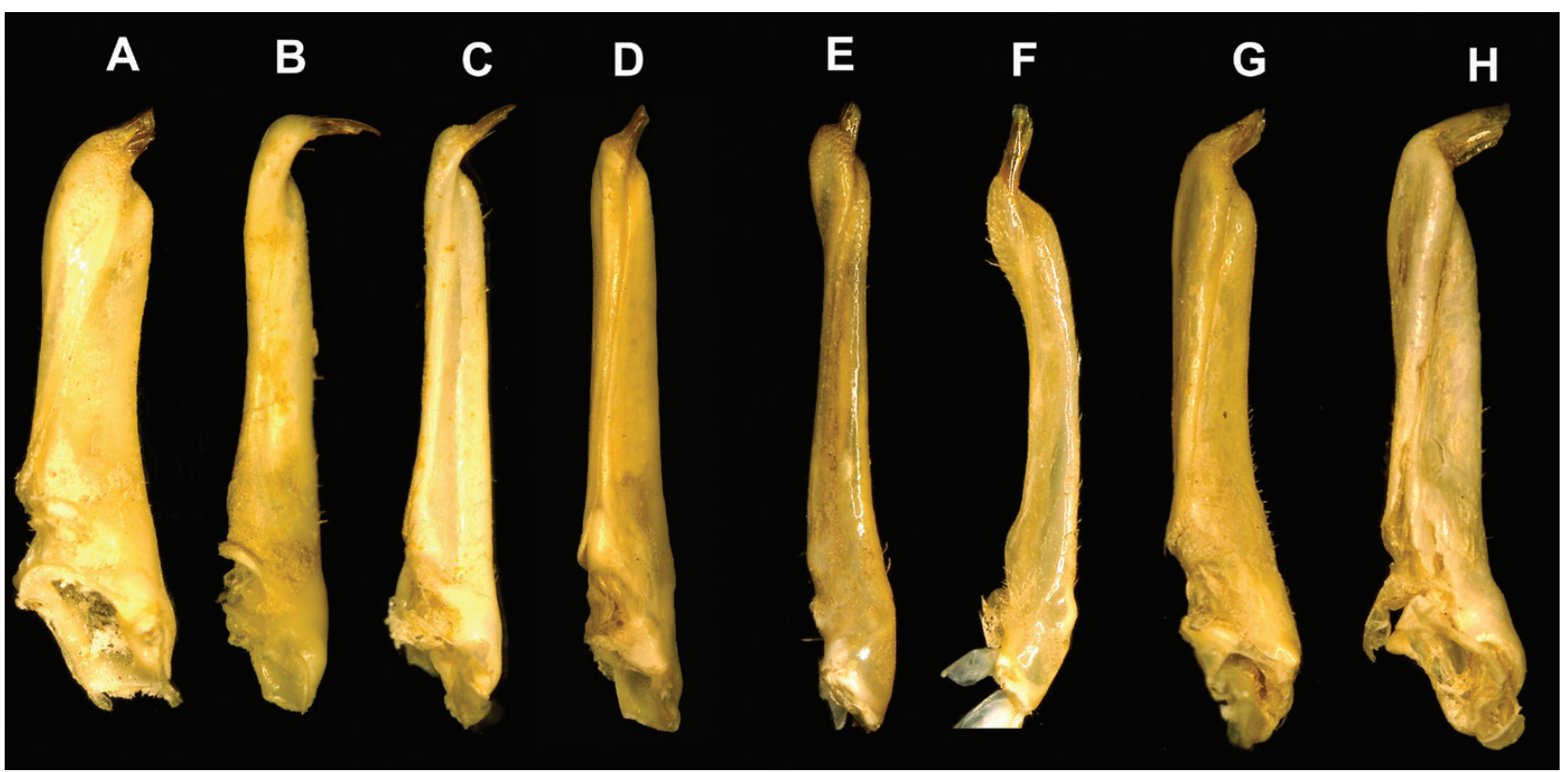

Figure 10. Morphology of right G1 in selected species of Parasesarma: A-D, members of Parasesarma plicatum group; E-H, members of Parasesarma leptosoma clade. A, Parasesarma pictum (19.8 mm × 17.6 mm; ZSM-A20171191), Japan: Hiroshima. B, Parasesarma tripectinis $(9.9 \mathrm{~mm} \times 8.0 \mathrm{~mm}$; ZSM-A20171189), Taiwan: Chunan Hsintong. C, P. plicatum (17.6 mm $\times 14.1 \mathrm{~mm}$; NHMW 1637), Ceylon. D, Parasesarma tuerkayi (28.2 mm × $24.0 \mathrm{~mm}$; QM-W28348), Vietnam: Tan Thoi Island. E, P. leptosoma (19.0 mm × 17.5 mm; MZUF 4978), Kenya: Mida Creek. F, Parasesarma gazi (15.5 mm $\times 13.1$ mm; MZUF 3671), Kenya: Gazi Bay. G, Parasesarma moluccense (14.6 mm × 13.6 mm; RMNH.CRUS.D102590), Indonesia: Flores. H, Parasesarma jamelense (11.5 mm × 10.0 mm; USNM 45917), Philippines: Luzon.

character for many species identifications (Fig. 10), but does not necessarily exhibit a consistent difference between major phylogenetic groups. This irregular pattern of G1 diversity has been documented previously, for example in the case of the Chiromantes obtusifrons (Dana, 1851) species complex (Davie \& Ng, 2013). It appears that the G1 shape is often one of the first steps of morphological differentiation during reproductive isolation in speciation processes. For example, both $P$. pictum (Fig. 10A) and P. tripectinis (Fig. 10B), in addition to P. leptosoma (Fig. 10E) and P. gazi (Fig. 10F), are phylogenetically close species with conspicuously different G1. It thus appears that morphological divergence of the G1 can be a rapid mechanism evolving to prevent hybridization.

Following the above reasoning, it thus seems that different evolutionary mechanisms (allopatric speciation, hybridization and evolution of reproductive barriers) might have contributed to triggering a rapid speciation within both clades of Parasesarma. Proportionally fast changes in the morphology of dactylar tubercles and G1 were followed by the divergence of pectinated crest patterns, resulting in the formation of different evolutionary lineages with many newly evolved species, as in the case of these two groups of Parasesarma.

The remarkably low COX1 genetic distances among the newly described long-legged species by $\mathrm{Li}$ et al. (2018) (e.g. between $P$. gecko and P. tarantula; see Results) might also be a result of a historical mitochondrial introgression event, as shown in the case of P. gazi and P. leptosoma (see Cannicci et al., 2017). Alternatively, it could be the result of rapid evolution causing fast morphological deviation that cannot be detected in genetic markers such as the mitochondrial DNA COX1. However, using highly variable nuclear markers (e.g. microsatellites) might help to address their phylogeny with more certainty.

In the more recent literature, Parasesarma has been divided into two morphogroups, based on their ambulatory legs, i.e. the long-legged vs. the shortlegged ones (Rahayu \& Ng, 2009, 2010; Li et al., 2018). Congruently, in the present phylogeny the clade of $P$. leptosoma contains species with proportionally long ambulatory legs (P4). Members of the P. plicatum group include some long-legged species (e.g. $P$. pictum), but most of them have proportionally shorter ambulatory legs. However, the phylogenetic value of this character has been questioned before, because it 
can be an ecological response to the respective lifestyle and habitat. This has been reported for mangrove tree-climbing crabs as a case of convergent evolution (Fratini et al., 2005) and intraspecifically in freshwater crabs of the genus Sesarma that show longer and more slender legs in subterranean habitats (Schubart et al., 2010).

Another character distinguishing the two groups of Parasesarma is their eye morphology. Both groups show a certain variability in the proportional length of the eyestalk, which may also be an ontogenic modification through individual development. However, our morphological comparisons show that in adult males, species of the P. leptosoma group have short and stout eyestalks compared with the longer eyestalks of the $P$. plicatum group. As a resulting morphological diagnosis related to eye shape, it can be claimed that species of the $P$. leptosoma group have proportionally deeper orbits in comparison to other members of Parasesarma (Fig. 8).

As a distinct monophyletic group, separated from other phylogenetic units and from the main cluster of Parasesarma, the sesarmid species forming the $P$. leptosoma group are here classified as a new genus, diagnosed by several morphological features (e.g. palm pectinated crests, chelar dactylar tubercles, ambulatory legs and eye morphology). Below, we establish the name Leptarma gen. nov. for this new genus.

\section{SYSTEMATIC ACCOUNT}

\section{SESARMIDAE DANA, 1851 \\ PARASESARMA De Man, 1895}

Type species: The Indian Cancer quadratus Fabricius, 1798 , which is a preoccupied name and a synonym of Ocypode plicatum Latreille, 1803 (subsequent designation by Rathbun, 1918; see Ng et al., 2008; Rahayu \& Ng, 2010).

Diagnosis: Small- to medium-sized crabs (usually $<25$ $\mathrm{mm} \mathrm{cw}$; largest specimen studied here, $\mathrm{cw}=29.4 \mathrm{~mm}$; see Table 1). Carapace rectangular (broader than long; cw/cl ranging from 1.13 to 1.38 in examined material), with carapace regions well defined: front moderately deflexed, with median concavity; four postfrontal lobes with median groove extending to gastric region (Figs 8A-G, 11A); gastric region well defined; lateral margins of carapace either without tooth, with shallow indentation or with epibranchial tooth of varying size. Eyestalk longer than wide, longer than corneal part in dorsal view; cornea almost as wide as eyestalk (Figs 8A-G, 9A). Male chelipeds robust; palm with one to three (usually two) oblique (more transverse) pectinated crests on upper surface (Fig. 5A-E), which consist of tall chitinous teeth, flanked by a large tubercle on inner side (Fig. 6A-C; except for P. gemmatum, which has a row of fine granules instead of the pectinated crest; see Remarks on this species); chelar dactylus dorsally with a row of tubercles; proximal tubercles at inner side of dorsal face, with virtual line of proximal dactylar tubercles directed towards inner tubercle of pectinated crests (Fig. 7A). Ambulatory legs dorsoventrally flattened, proportionally short (P4/cw ranges from 1.49 to 1.96 ; Figs $9 \mathrm{~B}, 11 \mathrm{~A})$. Pleon of male relatively short, triangular; somite 3 widest; somite 6 slightly longer than somite 5; telson small, slightly wider than long in most species. Female pleon broad, touching coxae of walking legs; vulvae on anterior part of sternite 6 .

Remarks: Members of this genus have experienced several rearrangements and taxonomic changes (e.g. Tesch, 1917; Serène \& Soh, 1970; Ng et al., 2008; Shahdadi \& Schubart, 2017), and many were originally described under different names (see Table 4). The genus is distributed exclusively in the IndoWest Pacific (for the type localities, see Table 4) and in our revised system now contains 54 nominal species that are listed in Table 4. For a list of synonyms, see $\mathrm{Ng}$ et al. (2008) and Shahdadi \& Schubart (2017).

The type species of Parasesarma, P. plicatum, has experienced a complicated and unstable taxonomic history until Rahayu \& Ng (2010) revised the taxonomy of this species and presumed allied taxa. These authors also recognized $P$. affine and Parasesarma ungulatum (H. Milne Edwards, 1853) as valid species, which were previously synonymized under $P$. plicatum by Tesch (1917). Our genetic results also confirmed the separate identities of these species, but did not recognize them as allies.

Shahdadi et al. (2019a) described P. austrawati from northern Australian mangroves and highlighted its phylogenetic position among other related species, focusing on $P$. lividum from the South Pacific and $P$. samawati from East Africa. However, P. lividum s.l. has been recorded from different places in Southeast Asia (Tesch, 1917; Shahdadi et al., 2018a; Li et al., 2019), and the phylogenetic and taxonomic positions of these populations are still unresolved.

Parasesarma bengalense (Davie, 2003) and Parasesarma haswelli (De Man, 1887) were described from the Bay of Bengal, i.e. P. bengalense from Sri Lanka (Davie, 2003) and P. hasswelli from the Mergui Archipelago (De Man, 1887; Table 4), and both have 16-19 chelar dactylar tubercles. While describing $P$. bengalense, Davie (2003) did not include P. hasswelli for comparison, but Davie (2010) diagnosed P. hasswelli in his identification key as having asymmetrical chelar dactylar tubercles (vertical distal slope) vs. symmetrical tubercles in $P$. bengalense. We examined the morphology of a series of $P$. bengalense specimens 


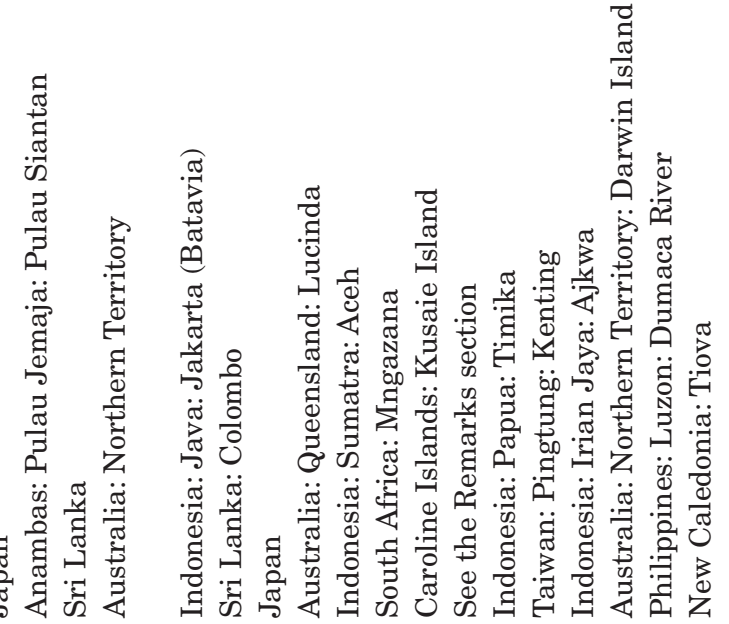

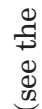

离

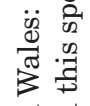

द्म

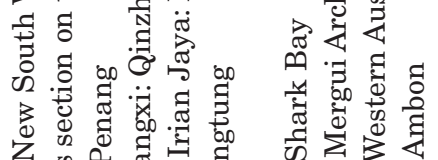

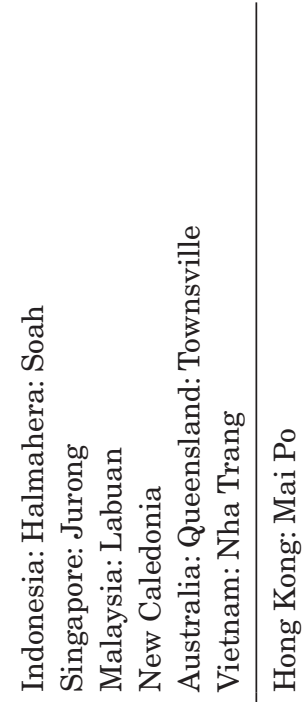

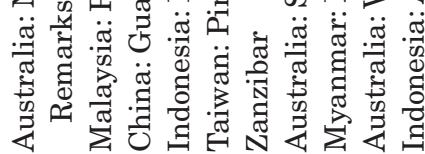

$\stackrel{2}{: 3}$

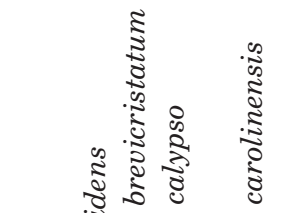

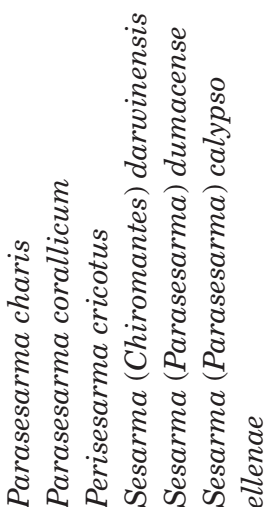

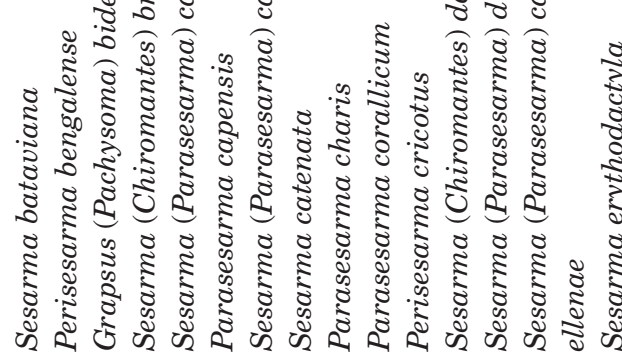

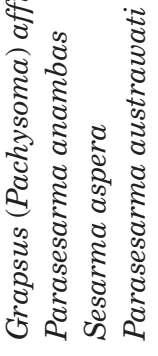

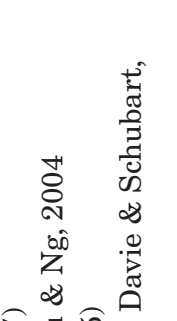
穴 (2)

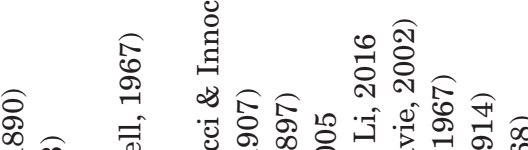
\%

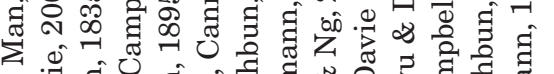

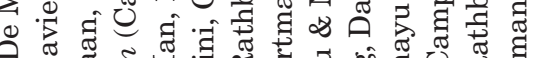
อ इ

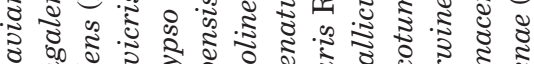

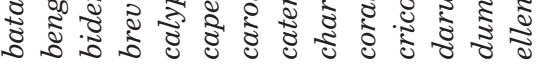

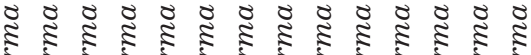
ปิ

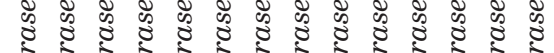
范<smiles>C1CCC2CC2C1</smiles>

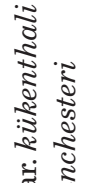

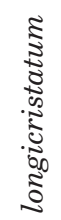

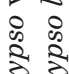
ช.

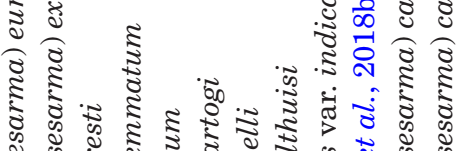

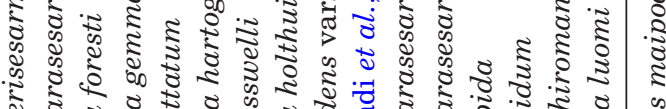

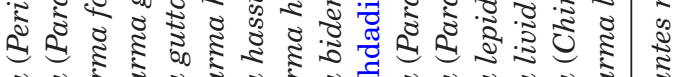

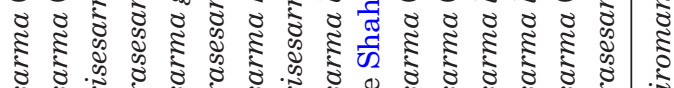

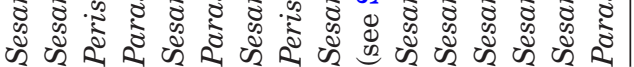
రิ 


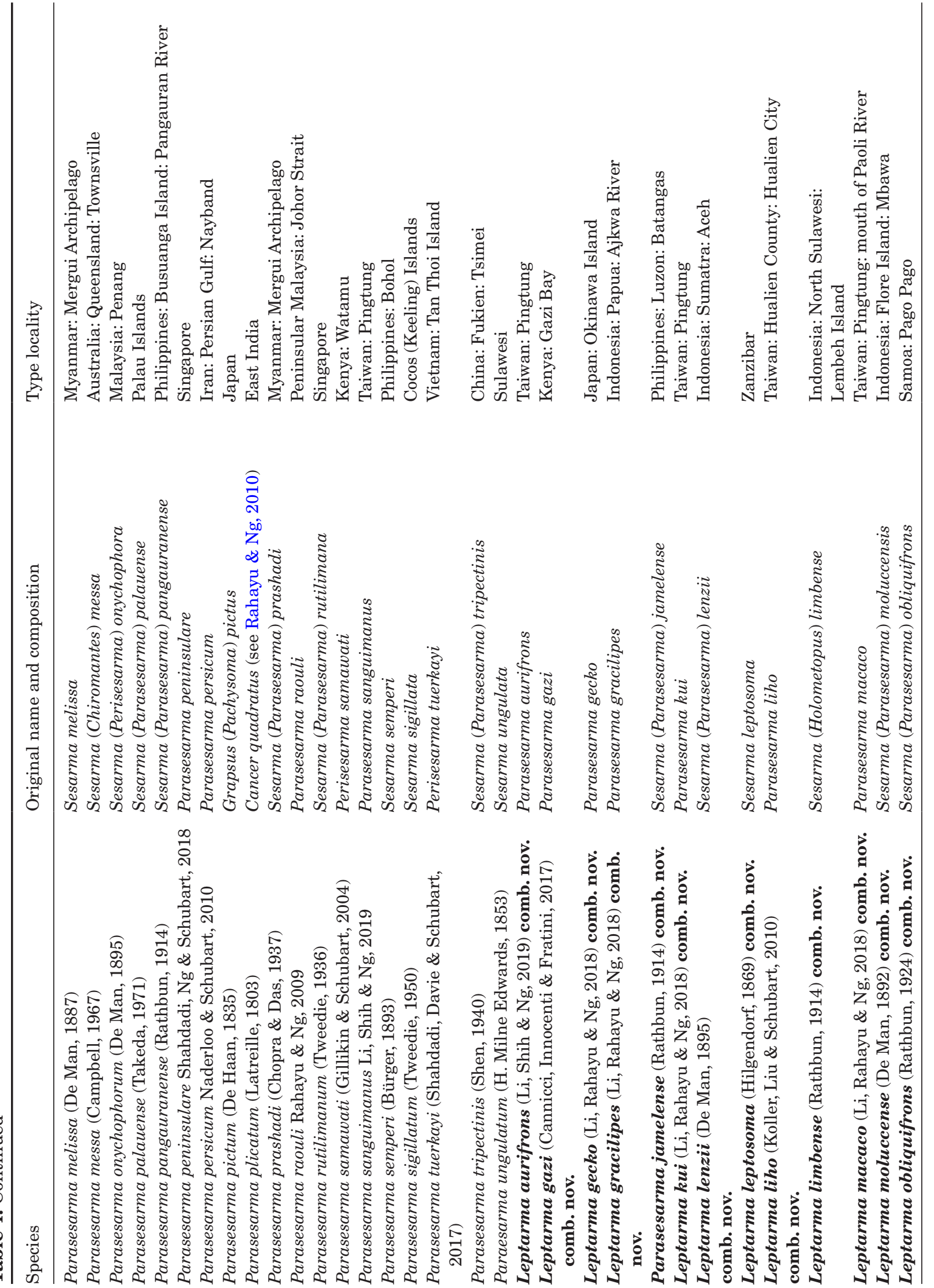




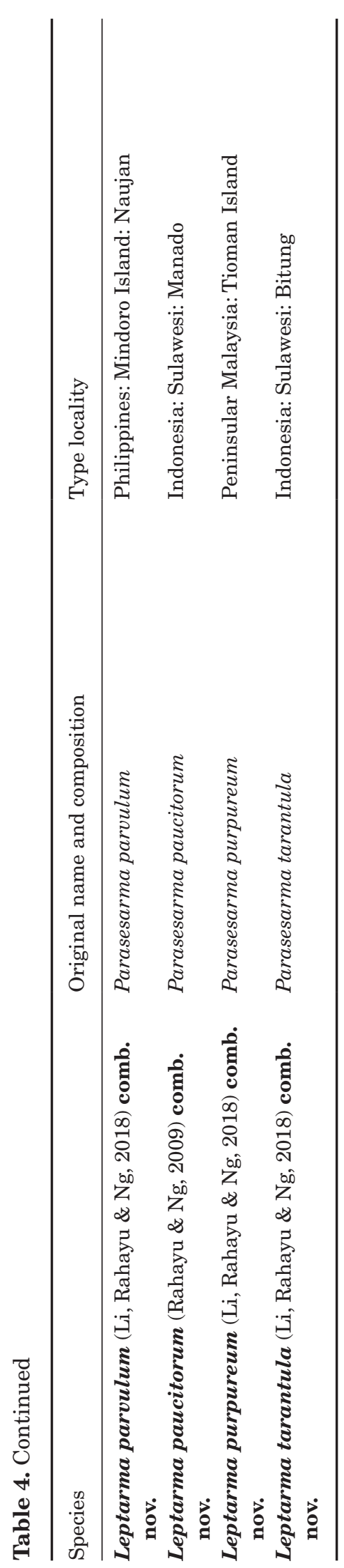

of different size (age) from different areas and also a small syntype of $P$. hasswelli (NHM London; see Table 1). It appears that smaller specimens have asymmetric tubercles, whereas in larger males these tubercles are symmetrically ovate. A possible hypothesis is that this difference is caused by a developmental change through ageing. However, morphological examination of more material of $P$. hasswelli and genetic comparison can help to address the doubt of conspecificity.

Parasesarma bidens was originally described from Japan by De Haan (1833) and was known to be distributed widely in Korea, Taiwan, the Philippines and along the Chinese coast to the Andaman Sea (Dai \& Yang, 1991). However, Li et al. (2019) described the new species Parasesarma sanguimanus $\mathrm{Li}$, Shih \& Ng, 2019 , based on some Taiwanese specimens that were shown to be morphologically and genetically distinct from the Japanese P. bidens and other members of Parasesarma. We here examined a male sample of $P$. sanguimanus from Bohol Island (Philippines), indicating an enlarged distribution of this new species beyond its type locality (for the material examined, see Table 1). The specimen from Bohol shares the same haplotype with the Taiwanese paratype in the barcode region of the COX1 gene (for the GenBank accession numbers, see Table 2).

In his description of $P$. catenatum, Ortmann (1897) mentioned New Zealand as its collection site, but he was not sure about the exact locality of the material. This species is common in East Africa (Fratini et al., 2005; Cannicci et al., 2017; Fratini et al., 2019), but there are no records from any other part of the world. We examined some specimens from East Africa and compared them with photographs of the type material (see section: Material examined) and they are identical in general morphology. Therefore, we assume that New Zealand as the collection site for the type must have been a labelling error. This species seems aberrant in chelar morphology in comparison to other Parasesarma species, because it has setae on the palm and dactylus and a wide gap between the fingers when closed (Emmerson, 2016). However, according to the phylogenetic position in this study and having two rows of transverse pectinated crests on the upper face of the palm and a long eyestalk, $P$. catenatum is assigned here within the genus Parasesarma.

While describing Parasesarma acis Davie, 1993 (which was later synonymized under $P$. tripectinis by Rahayu \& Ng, 2005), Davie (1993) also redescribed $P$. erythodactyla based on material collected from eastern Australia (deposited in the Queensland Museum and Museum of Victoria). He considered that the types of Hess' species (P. erythodactyla) are missing (for details about type history and material examined in the study, see Davie, 1993). He also separated the Australian $P$. erythodactyla from $P$. acis (now $P$. tripectinis) via 
several morphological characters (e.g. the morphology of G1 and chelar dactylar tubercles; Davie 1993: fig. 1). Our present generic assignment for this species is based on the description and illustration given by Davie (1993) and on the examination of three male specimens collected near Sydney (Table 1).

Given that no material of $P$. exquisitum is examined here, its generic assignment is based on the original description and illustrations (Dai \& Song, 1986) and new photographs (see section: Material examined).

In his identification key, Davie (2010) did not distinguish $P$. indiarum from Parasesarma foresti (Rahayu \& Davie, 2002), and their type localities are close (Ambon and Irian Jaya, respectively; De Man, 1902; Rahayu \& Davie, 2002; see Table 4). Genetic pairwise comparisons (K2P based on COX1) also revealed a close affinity between these two species (Shahdadi et al., 2017: table 3; Shahdadi et al., 2018b: table 2). Based on this evidence, they may be considered conspecifics, and their taxonomy needs to be evaluated by examining material from their entire area of distribution, including the type material.

The phylogeographic study by Silva et al. (2010) showed that Parasesarma guttatum (A. MilneEdwards, 1869) forms two separate clades in the south and north of Mozambique. Confirming this separation, Fratini et al. (2019) recently split $P$. guttatum into two pseudocryptic species, of which the newly described $P$. capensis Fratini, Innocenti \& Cannicci, 2019 is endemic to mangrove forests south of the Mozambique Channel. Thus, P. guttatum (whose type specimen, described by Alphonse Milne-Edwards in 1869, was from Zanzibar) is now restricted to populations distributed from the Gulf of Oman (Naderloo, 2011) and the Red Sea to northern Mozambique (Fratini et al., 2019).

Four species $[P$. calypso, P. ellenae, P. kuekenthali and $P$. lanchesteri (Tweedie, 1936)] were originally described as subspecies of $P$. calypso (see Table 4), sharing longitudinal lines on the proximal slopes of the chelar dactylar tubercles (De Man, 1895, 1902; Tweedie, 1936; Pretzmann, 1968). Accordingly, three of them cluster tightly together in our phylogenetic analyses, whereas $P$. lanchesteri is more distantly related (Fig. 2). Parasesarma ellenae was the latest described species of this group. Pretzmann (1968) briefly described this species based on a single small male from New Caledonia (Table 1) and highlighted differences from other members of the $P$. calypso group. For the present study, we examined the holotype, which turned out to be a juvenile male with undeveloped G1. Here, we also examined an adult male from New Caledonia and two larger males from Vanuatu Island (Table 1). A separate study will provide a detailed redescription of $P$. ellenae along with morphological comparisons with other related species.
Parasesarma panguaranense was originally described based on a single female (Rathbun, 1914), with no further record. In our study, we examined the holotype of this species, but we were not able to study any male specimen or to obtain any sequences from the type locality. Therefore, our generic assignment is based merely on structures such as orbit and eye morphology (Fig. 11B), which are assumed to be less affected by sexual dimorphism. More specimens from both sexes are necessary to confirm the taxonomy and phylogeny of the species.

Parasesarma rutilimanum was described from Singapore (Tweedie, 1936), and 1 year later Parasesarma prashadi (Chopra \& Das, 1937) was described from the nearby Mergui Archipelago without a comparison to $P$. rutilimanum. According to their original descriptions and illustrations, these two species show high morphological similarity in their general appearance (e.g. carapace morphology, ambulatory legs, number of chelar dactylar tubercles and long primary pectinated crest) and might be conspecific. In the present study, we examined a series of material from Phuket (Thailand), Singapore, Labuan (Malaysia) and a syntype of $P$. rutilimanum (from Pulau Senang). It is hard to distinguish the two species morphologically, and therefore in this study species assignments were based on their geography (i.e. specimen from Phuket as P. prashadi; specimens from Singapore and Labuan as $P$. rutilimanum). In this study, we were not able to examine the type of $P$. prashadi and we did not obtain any DNA sequence from $P$. rutilimanum. Therefore, a targeted study examining the corresponding type material and additional specimens from their distribution area should address this taxonomic issue.

Parasesarma corallicum and P. sigillatum show close genetic affinity in our mitochondrial analyses (Fig. 2). Parasesarma sigillatum was synonymized under $P$. carolinense by Serène (1968) and being treated as such until Ng et al. (2016) clarified the identities of $P$. carolinense and P. sigillatum and showed that they are separate species. Ng et al. (2016) also presented several morphological diagnoses to separate $P$. corallicum, $P$. carolinense and P. sigillatum.

Shahdadi et al. (2017) described P. tuerkayi as a member of the genus Perisesarma in the special volume dedicated to Michael Türkay, because the generic rearrangement by Shahdadi \& Schubart (2017) had not yet been published. However, at the end of their paper, Shahdadi et al. (2017: p. 1175) clarified in an addendum that this species would become a member of Parasesarma.

Parasesarma gemmatum was recently described by Li et al. (2019) from Taiwan. A male specimen of this species, collected from Cebu Island (Philippines), was also examined in the present study, matching 


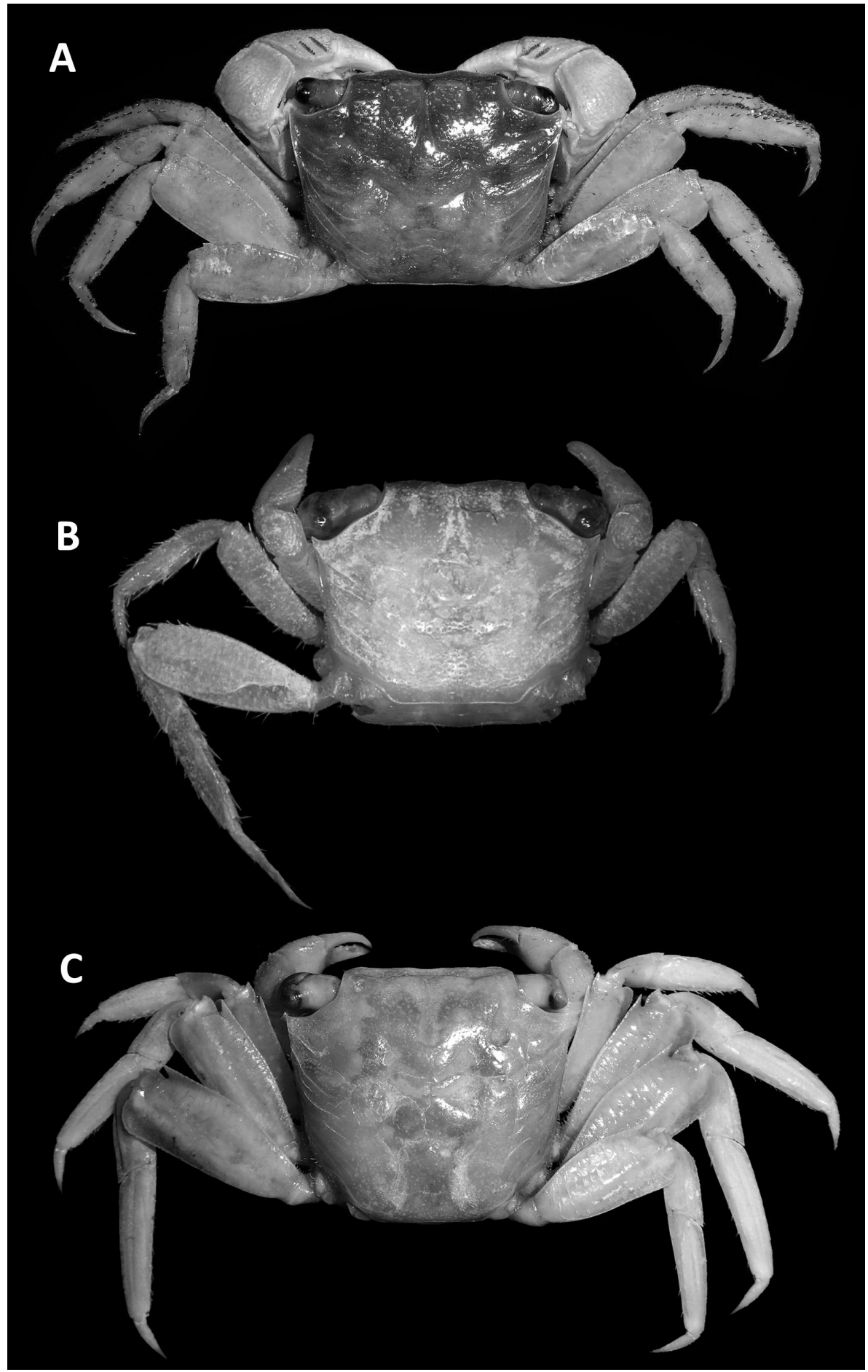

Figure 11. Dorsal habitus. A, Parasesarma plicatum male (22.4 mm $\times 17.8 \mathrm{~mm}$; SMF 49918), Thailand: Phuket. B, Parasesarma pangauranense female (6.0 mm $\times 4.9 \mathrm{~mm}$; USNM 45909 holotype), Philippines: Busuanga Island. C, Leptarma leptosoma female $(17.0 \mathrm{~mm} \times 16.0 \mathrm{~mm}$; ZMB 3181, holotype), Zanzibar.

all diagnostic characters of the Taiwanese types. Genetically, there is only 1 bp difference between the Cebu specimen and the Taiwanese paratype (i.e. $\sim 0.2 \%$ of genetic distance; for the GenBank accession numbers, see Table 2). Although this species is similar to other species of Parasesarma in general carapace 
and chelar morphology, it differs by having rows of fine granules and no chitinous pectinate crest on the palm (Li et al., 2019; present study). According to its phylogenetic position in the mitochondrial tree (Fig. 2; see also Li et al., 2019: fig. 13), this species is well nested within the $P$. plicatum clade. Therefore, it appears that $P$. gemmatum could have lost the pectinated crest secondarily. This might also be the case for Guinearma kamermani (De Man, 1883), a West African sesarmid crab that, in comparison to its congeners [i.e. Guinearma alberti (Rathbun, 1921) and Guinearma huzardi (Desmarest, 1825)], has lost the oblique pectinated crest (Shahdadi et al., 2019b).

\section{LEPTARMA GEN. NOV.}

lsid: zoobank.org:act:E4B034FF-1F44-434D-AC6770CDE0D2E078

Type species: Leptarma leptosoma (Hilgendorf, 1869) comb. nov. = Sesarma leptosoma Hilgendorf, 1869, present designation.

Diagnosis: Small crabs (usually cw $<20 \mathrm{~mm}$; largest specimen examined here with $\mathrm{cw}=20.8 \mathrm{~mm}$; Table 1 ). Carapace almost squarish (slightly broader than long; the ratio $\mathrm{cw} / \mathrm{cl}$ ranges from 1.06 to 1.21 in examined material). Carapace regions well defined: front moderately deflexed, with median concavity; four postfrontal lobes; median groove extending to gastric region (Figs 8H-N, 11C); gastric region well defined (Fig. 11C). Eyestalk shorter than wide in dorsal view; cornea wider than eyestalk (Figs 8H-N, 9A). Male chelipeds robust, palm with one or two (usually two) oblique (more longitudinal) pectinated crests on the upper surface (Fig. 5F, G), which consist of tall chitinous teeth, each flanked by large tubercle on the inner side and a line of coarse granules on the outer side, which creates a ridge, dividing the upper surface of the palm into two separate parts (outer and inner; Fig. 6D-F); chelar dactylus dorsally with a row of tubercles; proximal tubercles at middle of dactylar dorsal face; a virtual line of dactylar tubercles proximally would be directed towards the outer tubercle of the distal pectinated crest (Fig. 7B). Ambulatory legs dorsoventrally flattened, proportionally long ( $\mathrm{P} 4 /$ $\mathrm{cw}$ ranges from 1.81 to 2.2 ; Figs $9 \mathrm{~B}, 11 \mathrm{C})$. Pleon of male triangular; somite 3 widest and somite 6 longest. Female vulvae on the anterior part of sternite 6 .

Etymology: The name Leptarma is composed of the Greek $\lambda \varepsilon \pi \tau$ ós, leptos, thin, referring to the name of the type species epithet leptosoma, derived from $\lambda \varepsilon \pi \tau$ ó $\sigma \omega \mu \alpha$, thin body, which in turn refers to the slim walking legs of the comprised representatives, and the suffix -arma, derived from the last part of the genus

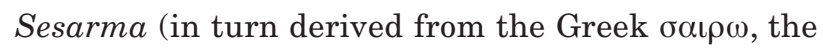
act of gaping; Say, 1817). The genus is gender neuter.

Remarks: This new genus includes 17 species as listed in Table 4, which were previously assigned to the genus Parasesarma (see Ng et al., 2008; Shahdadi \& Schubart, 2017; Li et al., 2018, 2019).

Our morphological comparisons and genetic results revealed that two species with neighbouring distribution ranges, viz. Leptarma moluccense (De Man, 1892) comb. nov. and Leptarma paucitorum (Rahayu \& Ng, 2009) comb. nov. (Indonesia: Flores Island and Sulawesi, respectively; for type localities, see Table 4), have a close relationship (see Fig. 1, ML tree). The description and comparison of $L$. paucitorum by Rahayu \& Ng (2009) did not include L. moluccense. Here, we suggest targeted morphological and genetic comparisons in order to evaluate the validity of $L$. paucitorum.

Leptarma lenzii (De Man, 1895) comb. nov. was originally described from Aceh (Indonesia: Sumatra; De Man, 1895) and was later recorded from the Cocos (Keeling) Islands (Tweedie, 1950). In the redescription of $P$. sigillatum from the Cocos (Keeling) Islands, $\mathrm{Ng}$ et al. (2016) noted that specimens of a taxon allied to L. lenzii were also obtained. Shahdadi et $a l$. (2019c) confirmed the identity of material from the Cocos (Keeling) Islands after morphological and genetic comparisons. Recently, Li et al. (2019) recorded this species from Taiwan and confirmed the identity using morphology and COX1 as the genetic marker. However, Shahdadi et al. (2019c) doubted the identities of what has been reported as 'Parasesarma lenzii' from Fiji (De Man, 1889: 434), the Moluccas (De Man, 1902: 536) and the Flores Sea (Tesch, 1918: 114). The material of Crosnier (1965; one male and one female) from Madagascar and the specimen of Poupin et al. (2012; one male) from Europa Island, which were reported as 'Parasesarma lenzii', were also examined for the present study (see Table 1: material examined of $P$. gazi). As a result of DNA degradation, PCR amplifications failed for the specimens of Crosnier (1965). Both G1 of the male specimen from Madagascar were also missing. However, the specimens resemble $L$. gazi (Cannicci, Innocenti, \& Fratini, 2017) comb. nov. in other features, as previously assigned by Cannicci et $a l$. (2017) according to the drawings given by Crosnier (1965). The specimen from Europa Island differs from both $L$. gazi and L. lenzii and from other species of Leptarma and will therefore be described as a new species. The ZRC specimens from Singapore that were identified as 'P. lenzii' were also examined. According to their horseshoe-like chelar dactylar tubercles, they are identified as P. melissa (e.g. ZRC 2000.1955; see Table 1). 
Leptarma kui (Li, Rahayu \& Ng, 2018) comb. nov. was described from Taiwan and is here reported from Cebu (Philippines). We have examined two male specimens, one from Cebu and one from Taiwan (Table 1), and both match the diagnostic characters described by Li et al. (2018). There is only one mutation in the barcode region of COX1 between the sequences from Cebu and the holotype of L. kui (for the GenBank accession numbers, see Table 2).

After morphological re-examinations and genetic comparisons of the types and extra material of $P$. cognatum and Leptarma liho (Koller, Liu \& Schubart, 2010) comb.nov., Shihet al. (2019)identified P.cognatum as a junior synonym of $L$. liho, which is now known from Japan (Okinawa, Miyako and Ishigaki), Taiwan (Hualien, Taitung and Pingtung), the Philippines (Cebu) and Indonesia (Sulawesi). Leptarma liho also resembles Leptarma jamelense (Rathbun, 1914) comb. nov. from Luzon (Philippines) in its general and G1 morphology. Koller et al. (2010) did not include $L$. jamelense for comparison in their description of $L$. liho as a new species. In the present study, the DNA amplification from $L$. jamelense was unsuccessful owing to DNA degradation. A targeted sampling from the type locality of L. jamelense (Philippines: Luzon: Batangas) and genetic comparisons should clarify this uncertainty.

The present generic assignment of Leptarma aurifrons ( $\mathrm{Li}$, Shih \& Ng, 2019) comb. nov. is based on its position in the mitochondrial phylogenetic tree (Fig. 2; see also Li et al., 2019: fig. 13). In our mitochondrial tree (Fig. 2), L. aurifrons is nested in the Leptarma clade, clustering with $L$. moluccense, $L$. paucitorum and L. liho. This is confirmed by the presence of proximal tubercles positioned on the mid-dorsal face of the chelar dactylus (see Li et al., 2019: fig. 4C), which is one of the diagnostic characters of Leptarma.

\section{ACKNOWLEDGEMENTS}

We are indebted to many institutions and colleagues that/who facilitated specimens, allowed access to samples or assisted in the field. Among those, our special thanks go to Peter K. L. Ng, Jose Christopher E. Mendoza, Muhammad Dzaki Bin Safaruan, Ngan Kee $\mathrm{Ng}$, Lee Be Yan, Ting Hui Ng and Wendy Wang Yanling from the National University of Singapore (Singapore); to Peter J. F. Davie and Marissa McNamara from the Queensland Museum in Brisbane (Queensland, Australia); to Angelika Brandt, Kristin Arnold, Moritz Sonnewald and Bianca Trautwein from the Senckenberg Museum in Frankfurt (Germany); to Charles Fransen and Karen van Dorp from Naturalis Biodiversity Center in Leiden (The Netherlands); to Paul Clark and Miranda Lowe from the Natural History Museum in London (UK); to Gianna Innocenti and Stefano Cannicci from the University of Florence (Italy); to Laure Corbari, Paula Martin-Lefèvre and Danièle Guinot from the Muséum National d'Histoire Naturelle, Paris (France); to Andrew Hosie and Ana Hara from the Western Australian Museum in Perth (WA, Australia); to Dwi Listyo Rahayu from the Indonesian Institute of Sciences, Jakarta (Indonesia); to Tomoyuki Komai from the Natural History Museum and Institute Chiba (Japan); to Tohru Naruse from the University of the Ryukyus (Japan); to Stephen Keable, Shane T. Ahyong, Helen Stoddart and Alex Hegedus from the Australian Museum in Sydney (NSW, Australia); to Peter C. Dworschak from the Naturhistorisches Museum Wien, Vienna (Austria); to Roland Melzer and Stefan Friedrich from the Zoologische Staatssammlung München, Munich (Germany); to Charles Oliver Coleman from the Museum für Naturkunde Berlin (Germany); to Rafael Lemaitre, Lisa Comer and Karen Reed from the Smithsonian Institution, Washington (DC, USA); to Paul Callomon from the Academy of Natural Sciences of Drexel University, Philadelphia (PA, USA); to Hsi-Te Shih from National Chung Hsing University, Taichung (Taiwan); and to Gustav Paulay from the Florida Museum of Natural History, Gainesville (FL, USA). The first author's visits to Naturalis in Leiden (the Netherlands) (NL-TAF), the Natural History Museum in London (UK) (GB-TAF) and to the Muséum National d'Histoire Naturelle, Paris (France) (FR-TAF) received support from the SYNTHESYS Project (http:// www.synthesys.info/), financed by the European Community, Research Infrastructure Action under the FP7 'Capacities', which is greatly appreciated. We also thank Peter K. L. Ng and Tohru Naruse for their useful comments during the review process.

\section{REFERENCES}

Boon PY, Yeo DCJ, Todd PA. 2009. Sound production and reception in mangrove crabs Perisesarma spp. (Brachyura: Sesarmidae). Aquatic Biology 5: 107-116.

Brösing A, Spiridonov VA, Al-Aidaroos AM, Türkay M. 2014. Description of a new genus and new species of Sesarmidae (Decapoda: Brachyura) from the Farasan Islands, Saudi Arabia, Red Sea. Journal of Crustacean Biology 34: 273-282.

Cannicci S, Burrows D, Fratini S, Smith TJ III, Offemberg J, Dahdouh-Guebas F. 2008. Faunal impact on vegetation structure and ecosystem function in mangrove forests: a review. Aquatic Botany 89: 186-200.

Cannicci S, Schubart CD, Innocenti G, Dahdouh-Guebas F, Shahdadi A, Fratini S. 2017. A new species of the genus Parasesarma De Man 1895 from East African mangroves and evidence for mitochondrial introgression in sesarmid crabs. Zoologischer Anzeiger 269: 89-99. 
Chen P, Carrasco L, Ng PKL. 2014. Post-contest stridulation used exclusively as a victory display in mangrove crabs. Ethology 120: 532-539.

Chen P, Carrasco L, Ng PKL. 2017. Mangrove crab uses victory display to "browbeat" losers from re-initiating a new fight. Ethology 123: 981-988.

Chopra B, Das KN. 1937. Further notes on Crustacea Decapoda in the Indian Museum. IX. On three collections of crabs from Tavoy and Mergui archipelago. Records of the Indian Museum 39: 377-434.

Crosnier A. 1965. Crustacés décapodes Grapsidae et Ocypodidae. Faune de Madagascar 18: 1-143, pl. 1-11.

Dai A, Song YZ. 1986. Intertidal crabs from Beibu Gulf of Guangxi. Transactions of the Chinese Crustacean Society 1: $54-62$.

Dai A, Yang S. 1991. Crabs of the China seas. Beijing: China Ocean Press (Chinese edition); Berlin, Heidelberg, New York, Tokyo: Springer (English edition).

Darriba D, Taboada GL, Doallo R, Posada D. 2012. jModelTest 2: more models, new heuristics and parallel computing. Nature Methods 9: 772.

Davie PJF. 1992. Revision of Sarmatium Dana (Crustacea: Brachyura: Sesarminae) with descriptions of three new species. Memoirs of the Queensland Museum 32: 79-97.

Davie PJF. 1993. A new species of sesarmine crab (Brachyura: Grapsidae) from Japan and Taiwan, previously known as Sesarma erythrodactyla Hess, 1865. Crustacean Research 22: 65-74.

Davie PJF. 1994. Revision of the genus Neosarmatium Serene and Soh (Crustacea: Brachyura: Sesarminae) with description of two new species. Memoirs of the Queensland Museum 35: 35-74.

Davie PJF. 2003. A new species of Perisesarma (Crustacea: Brachyura: Sesarmidae) from the Bay of Bengal. The Raffles Bulletin of Zoology 51: 387-391.

Davie PJF. 2010. A new species of Perisesarma (Crustacea: Brachyura: Sesarmidae) from Western Australia. In: Fransen CHJM, De Grave S, Ng PKL, eds. Studies on Malacostraca: Lipke Bijdeley Holthuis memorial volume. Crustaceana monographs, Leiden: Brill, Vol. 14, 195-207.

Davie PJF. 2012. A revision of Neosesarma (Crustacea: Decapoda: Sesarmidae) with the description of a new species. Memoirs of the Queensland Museum 56: 221-233.

Davie PJF, Ng PKL. 2013. A review of Chiromantes obtusifrons (Dana, 1851) (Decapoda: Brachyura: Sesarmidae), with descriptions of four new sibling-species from Christmas Island (Indian Ocean), Guam and Taiwan. Zootaxa 3609: 1-25.

De Grave S, Pentcheff ND, Ahyong ST, Chan TY, Crandall KA, Dworschak PC, Felder DL, Feldmann RM, Fransen CHJM, Goulding LYD, Lemaitre R, Low MEY, Martin JW, Ng PKL, Schweitzer CE, Tan SH, Tshudy D, Wetzer R. 2009. A classification of living and fossil genera of decapod crustaceans. The Raffles Bulletin of Zoology, Supplement 21: $1-109$.

De Haan HM. 1833-1849. Crustacea [vol. 1]. In: von Siebold PF, ed. Fauna Japonica, sive descriptio animalium, quae in itinere per Japoniam, jussu et auspiciis superiorum, qui summum in India Batavia imperium tenent, suscepto, annis
1823-1830 collegit, notis, observationibus a adumbrationibus illustravit. Leiden: published by the author, 1-243.

De Man JG. 1887. Uebersicht der Indo-pacischen Arten der Gattung Sesarma Say nebst einer Kritik der von W. Hess und E. Nauck in den Jahren 1865 und 1880 beschriebenen Decapoden. Zoologische Jahrbücher. Abteilung für Anatomie und Ontogenie der Tiere 2: 639-689.

De Man JG. 1889. Über einige neue oder seltene indopacifische Brachyuren. Zoologische Jahrbücher. Abteilung für Systematik, Geographie und Biologie der Tiere 4: 409-452.

De Man JG. 1892. Decapoden des Indischen Archipels. Zoologische Ergebnisse einer Reise in Niederländisch OstIndien 2: 265-527.

De Man JG. 1895-1898. Bericht über die von Herrn Schiffscapitän Storm zu Atjeh, an den westlichen Küsten von Malakka, Borneo und Celebes sowie in der Java-See gesammelten Decapoden und Stomatopoden. Zoologische Jahrbücher, Abtheilung für Systematik, Geographie und Biologie der Thiere 9: 75-218.

De Man JG. 1902. Die von Herr Professor Kükenthal im Indischen Archipel gesammelten Dekapoden und Stomatopoden. In: Kükenthal W, ed. Ergebnisse einer Zoologischen Forschungsreise in den Molukken und Borneo. Abhandlungen der Senckenbergischen Naturforschenden Gesellschaft 25: 467-929.

Emmerson WD. 2016. A guide to, and checklist for, the Decapoda of Namibia, South Africa and Mozambique, Newcastle: Cambridge Scholars Publishing, Vol. 3: $1-720$.

Folmer O, Black M, Hoeh W, Lutz R, Vrijenhoek R. 1994. DNA primers for amplification of mitochondrial cytochrome c oxidase subunit I from diverse metazoan invertebrates. Molecular Marine Biology and Biotechnology 3: 294-299.

Fratini S, Cannicci S, Porri F, Innocenti G. 2019. Revision of the Parasesarma guttatum species complex reveals a new pseudocryptic species in south-east African mangroves. Invertebrate Systematics 33: 208-224.

Fratini S, Vannini M, Cannicci S, Schubart CD. 2005. Treeclimbing mangrove crabs: a case of convergent evolution. Evolutionary Ecology Research 7: 219-233.

Guerao G, Anger K, Nettelmann U, Schubart CD. 2004. Complete larval and early juvenile development of the mangrove crab Perisesarma fasciatum (Crustacea: Brachyura: Sesarmidae) from Singapore, with a larval comparison of Parasesarma and Perisesarma. Journal of Plankton Research 26: 1389-1408.

Guindon S, Gascuel O. 2003. A simple, fast and accurate method to estimate large phylogenies by maximum likelihood. Systematic Biology 52: 696-704.

Guinot D. 1977. Propositions pour une nouvelle classification des crustacés décapodes brachyoures. Comptes Rendus Hebdomadaires des Séances de l'Académie des Sciences, série D 285: 1049-1052.

Hall TA. 1999. BioEdit: a user-friendly biological sequence alignment editor and analysis program for Windows 95/98/ NT. Nucleic Acids Symposium Series 41: 95-98.

Hess W. 1865. Beiträge zur Kenntniss der DecapodenKrebse Ost-Australiens der philosophischen Facultät 
der Georg-August-Universität in Göttingen. Archiv für Naturgeschichte 31: 127-173.

Hilgendorf F. 1869. Crustaceen. In: Von der Decken CC, ed. Reisen in Ost-Afrika in dem Jahren 1859-1865, Vol. 3. Leipzig, Heidelberg: C.F. Winter'sche Verlagshandlung, 69-116.

Huelsenbeck JP, Ronquist F. 2001. MRBAYES: Bayesian inference of phylogenetic trees. Bioinformatics 17: 754-755.

Koller P, Liu H-C, Schubart CD. 2010. A new semiterrestrial species of Parasesarma De Man, 1895, from Taiwan (Decapoda, Brachyura, Sesarmidae). In: Fransen CHJM, De Grave S, Ng PKL, eds. Studies on Malacostraca: Lipke Bijdeley Holthuis memorial volume. Crustaceana Monographs, Leiden: Brill, Vol. 14: 357-368.

Lee SY. 1998. Ecological role of grapsid crabs in mangrove ecosystems: a review. Marine and Freshwater Research 49: 335-343.

Lee SY. 2015. Ecology of Brachyura. In: Castro P, Davie PJF, Guinot D, Schram F, von Vaupel Klein C, eds. Treatise on zoology - anatomy, taxonomy, biology - The Crustacea, complementary to the volumes translated from the French of the Traité de Zoologie, Leiden: Brill, Vol. 9(C) (I), 469-542.

Li J-J, Rahayu DL, Ng PKL. 2018. Identity of the tree-spider crab, Parasesarma leptosoma (Hilgendorf, 1869) (Decapoda: Brachyura: Sesarmidae), with descriptions of seven new species from the western Pacific. Zootaxa 4482: 451-490.

Li J-J, Shih HT, Ng PKL. 2019. Three new species and two new records of Parasesarma De Man, 1895 (Crustacea: Brachyura: Sesarmidae) from Taiwan and the Philippines from morphological and molecular evidence. Zoological Studies 58: e40.

Naderloo R. 2011. Grapsoid crabs (Decapoda: Brachyura: Thoracotremata) of the Persian Gulf and the Gulf of Oman. Zootaxa 3048: 1-43.

Naderloo R, Schubart CD. 2010. Description of a new species of Parasesarma (Crustacea; Decapoda; Brachyura; Sesarmidae) from the Persian Gulf, based on morphological and genetic characteristics. Zoologischer Anzeiger 249: 33-43.

Naruse T, Ng NK. 2012. Establishment of a new genus for Cyclograpsus lophopus Nobili, 1905, within Sesarmidae Dana, 1851 (Crustacea: Decapoda: Brachyura). Zootaxa 3572: $63-68$.

Ng PKL, Davie PJF, Li J-J. 2016. On the identities of Parasesarma carolinense (Rathbun, 1907) and Parasesarma sigillatum (Tweedie, 1950), with description of a new species from Taiwan (Crustacea: Brachyura: Sesarmidae). The Raffles Bulletin of Zoology 64: 257-268.

Ng PKL, Guinot D, Davie PJF. 2008. Systema brachyurorum: part I. An annotated checklist of extant brachyuran crabs of the world. The Raffles Bulletin of Zoology, Supplement 17: 1-286.

Ng PKL, Shih HT, Cannicci S. 2019. A new genus for Sesarma (Holometopus) tangi Rathbun, 1931 (Decapoda: Brachyura: Sesarmidae) from mangrove forests, with notes on its ecology and conservation. Journal of Crustacean Biology 40: 89-96.

Ortmann AE. 1897. Carcinologische Studien. Zoologische Jahrbücher, Abtheilung für Systematik, Geographie und Biologie der Thiere 10: 258-372.

Posada D, Buckley TR. 2004. Model selection and model averaging in phylogenetics: advantages of Akaike information criterion and Bayesian approaches over likelihood ratio tests. Systematic Biology 53: 793-808.

Poupin J, Zubia M, Chabanet P, Malay M. 2012. Illustrated checklist of the Decapoda at Europa Island. WIO Journal of Marine Science 11: 1-25.

Pretzmann G. 1968. Neue südamerikanische Süsswasserkrabben der Gattung Pseudothelphusa. Entomologisches Nachrichtenblatt 15: 1-15.

Ragionieri L, Fratini S, Vannini M, Schubart CD. 2009. Phylogenetic and morphometric differentiation reveal geographic radiation and pseudo-cryptic speciation in a mangrove crab from the Indo-West Pacific. Molecular Phylogenetics and Evolution 52: 825-834.

Rahayu DL, Davie PJF. 2002. Two new species and a new record of Perisesarma (Decapoda, Brachyura, Grapsidae, Sesarminae) from Indonesia. Crustaceana 75: 597-607.

Rahayu DL, Li J-J. 2013. A new species of the genus Parasesarma (Crustacea: Brachyura: Sesarmidae) from Taiwan and the Philippines, and redescription of $P$. jamelense (Rathbun, 1914). The Raffles Bulletin of Zoology 61: 633-639.

Rahayu DL, Ng PKL. 2005. On two new species of the genera Haberma and Parasesarma (Crustacea: Decapoda: Brachyura: Sesarmidae) from Papua, Indonesia. Zoologische Mededelingen 79: 167-178.

Rahayu DL, Ng PKL. 2009. Two new species of Parasesarma De Man, 1895, from Southeast Asia (Crustacea: Decapoda: Brachyura: Sesarmidae). Zootaxa 1980: 29-40.

Rahayu DL, Ng PKL. 2010. Revision of Parasesarma plicatum (Latreille, 1803) species-group (Crustacea: Decapoda: Brachyura: Sesarmidae). Zootaxa 2327: 1-22.

Rathbun MJ. 1914. New species of crabs of the families Grapsidae and Ocypodidae, in: scientific results of the Philippines Cruise of the fisheries steamer "Albatross" 1907-1910. Proceedings of the United States National Museum 47: 69-85.

Rathbun MJ. 1918. Brachyura. Australasian Antarctic Expedition, 1911-1914, under the leadership of sir Douglas Mawson, D. Sc., B.E. Scientific Reports, Series C, Zoology and Botany 5: 1-5.

Rodríguez F, Oliver JL, Marín A, Medina JR. 1990. The general stochastic model of nucleotide substitution. Journal of Theoretical Biology 142: 485-501.

Rohlf FJ. 2006. TpsDig, Version 2.10. Sony Brook: Department of Ecology and Evolution, State University of New York at Stony Brook.

Say T. 1817. An account of the Crustacea of the United States. Journal of the Academy of Natural Sciences of Philadephia 1: $57-81$.

Schubart CD. 2009. Mitochondrial DNA and decapod phylogenies: the importance of pseudogenes and primer optimization. In: Martin JW, Crandall KA, Felder DL, eds. Decapod Crustacean Phylogenetics. Crustacean Issues, Boca Raton: CRC Press, Vol. 18: 47-65.

Schubart CD, Cannicci S, Vannini M, Fratini S. 2006. Molecular phylogeny of grapsoid crabs (Decapoda, Brachyura) and allies based on two mitochondrial genes and a proposal for refraining from current superfamily classification. Journal of Zoological Systematics and Evolutionary Research 44: 193-199. 
Schubart CD, Cuesta JA, Felder DL. 2002. Glyptograpsidae, a new brachyuran family from Central America: larval and adult morphology, and a molecular phylogeny of the Grapsoidea. Journal of Crustacean Biology 22: 28-44.

Schubart CD, Huber MGJ. 2006. Genetic comparison of German populations of the stone crayfish, Austropotamobius torrentium (Crustacea: Astacidae). Bulletin Français de la Pêche et de la Pisciculture 380-381: 1019-1028.

Schubart CD, Liu H-C, Ng PKL. 2009. Revision of Selatium Serène \& Soh, 1970 (Crustacea: Brachyura: Sesarmidae), with description of a new genus and two new species. Zootaxa 2154: 1-29.

Schubart CD, Weil T, Stenderup JT, Crandall KA, Santl T. 2010. Ongoing phenotypic and genotypic diversification in adaptively radiated freshwater crabs from Jamaica. In: Glaubrecht M, ed. Evolution in action - adaptive radiations and the origins of biodiversity. Berlin, Heidelberg: Springer, 323-349.

Serène R. 1968. The Brachyura of the Indo Pacific Region. In: Prodromus for a Check List of the Non-planctonic Marine Fauna of South East Asia. Special Publication of the Singapore National Academy of Science 1: 33-120.

Serène R, Soh CL. 1970. New Indo-Pacific genera allied to Sesarma Say 1817 (Brachyura, Decapoda, Crustacea). Treubia 27: 387-416.

Shahdadi A, Davie PJF, Schubart CD. 2017. Perisesarma tuerkayi, a new species of mangrove crab from Vietnam (Decapoda, Brachyura, Sesarmidae), with an assessment of its phylogenetic relationships. Crustaceana 90: 1155-1175.

Shahdadi A, Davie PJF, Schubart CD. 2018a. Systematics and phylogeography of the Australasian mangrove crabs Parasesarma semperi and P. longicristatum (Decapoda: Brachyura: Sesarmidae) based on morphological and molecular data. Invertebrate Systematics 32: 196-214.

Shahdadi A, Davie PJF, Schubart CD. 2019a. A new species of Parasesarma (Decapoda: Brachyura: Sesarmidae) from northern Australian mangroves and its distinction from morphologically similar species. Zoologischer Anzeiger 279: 116-125.

Shahdadi A, Mvogo Ndongo PA, Suess T, Schubart CD. 2019b. Reappraisal and redescription of the three species of the recently defined genus Guinearma Shahdadi \& Schubart, 2017, with a key to the West African Sesarmidae (Decapoda, Brachyura). Crustaceana 92: 307-334.

Shahdadi A, Ng PKL, Schubart CD. 2018b. Morphological and phylogenetic evidence for a new species of Parasesarma De Man, 1895 (Decapoda, Brachyura, Sesarmidae) from the Malay Peninsula, previously referred to as Parasesarma indiarum. The Raffles Bulletin of Zoology 66: 739-762.

Shahdadi A, Schubart CD. 2015. Evaluating the consistency and taxonomic importance of cheliped and other morphological characters that potentially allow identification of species of the genus Perisesarma De Man, 1895 (Brachyura, Sesarmidae). Crustaceana 88: 1079-1095.

Shahdadi A, Schubart CD. 2017. Taxonomic review of Perisesarma (Decapoda: Brachyura: Sesarmidae) and closely related genera based on morphology and molecular phylogenetics: new classification, two new genera and the questionable phylogenetic value of the epibranchial tooth. Zoological Journal of the Linnean Society 182: 517-548.
Shahdadi A, Schubart CD, Ng PKL. 2019c. Record of Parasesarma lenzii (De Man, 1895) (Decapoda, Brachyura, Sesarmidae) from the Cocos-Keeling Islands, with a redescription and designation of a lectotype. Crustaceana 92: 739-747.

Shedlock AM, Haygood MG, Pietsch TW, Bentzen P. 1997. Enhanced DNA extraction and PCR amplification of mitochondrial genes from formalin-fixed museum specimens. BioTechniques 22: 394-400.

Shih HT, Hsu PY, Shahdadi A, Schubart CD, Li JJ. 2019. The synonymy of the supratidal crabs species Parasesarma cognatum Rahayu \& Li, 2013 with P. liho Koller, Liu \& Schubart, 2010 (Decapoda: Brachyura: Sesarmidae) based on morphological and molecular evidence, with a note on $P$. paucitorum Rahayu \& Ng, 2009. Zoological Studies 58: 1-13.

Silva IC, Mesquita M, Paula J. 2010. Genetic and morphological differentiation of the mangrove crab Perisesarma guttatum (Brachyura: Sesarmidae) along an East African latitudinal gradient. Biological Journal of the Linnean Society 99: 28-46.

Silvestro D, Michalak I. 2012. raxmlGUI: a graphical front-end for RAxML. Organisms Diversity \& Evolution 12: 335-337.

Tamura K, Peterson D, Peterson N, Stecher G, Nei M, Kumar S. 2011. MEGA5: molecular evolutionary genetics analysis using maximum likelihood, evolutionary distance, and maximum parsimony methods. Molecular Biology and Evolution 28: 2731-2739.

Tan CGS, Ng PKL. 1994. An annotated checklist of mangrove brachyuran crabs from Malaysia and Singapore. Hydrobiologia 285: 75-84.

Tesch JJ. 1917. Synopsis of the genera Sesarma, Metasesarma, Sarmatium and Clistocoeloma with a key to determination of the Indo-Pacific species. Zoologische Mededelingen 3: 127-260.

Tesch JJ. 1918. The Decapoda Brachyura of the Siboga expedition. I. Hymenosomidae, Retroplumidae, Ocypodidae, Grapsidae, and Gecarcinidae. Siboga-Expeditie Mon. 39: 1-148.

Thompson JD, Higgins DG, Gibson TJ. 1994. CLUSTAL W: improving the sensitivity of progressive multiple sequence alignment through sequence weighting, position-specific gap penalties and weight matrix choice. Nucleic Acids Research 22: 4673-4680.

Tsang LM, Ma KY, Ahyong ST, Chan TY, Chu KH. 2008. Phylogeny of Decapoda using two nuclear protein-coding genes: origin and evolution of the Reptantia. Molecular Phylogenetics and Evolution 48: 359-368.

Tsang LM, Schubart CD, Ahyong ST, Lai JC, Au EY, Chan TY, Ng PK, Chu KH. 2014. Evolutionary history of true crabs (Crustacea: Decapoda: Brachyura) and the origin of freshwater crabs. Molecular Biology and Evolution 31: 1173-1187.

Tweedie MWF. 1936. On the crabs of the family Grapsidae in the collection of the Raffles Museum. Bulletin of the Raffles Museum 12: 44-70.

Tweedie MWF. 1950. Grapsoid crabs from Labuan and Sarawak. Sarawak Museum Journal 5: 338-369.

Villesen P. 2007. FaBox: an online toolbox for FASTA sequences. Molecular Ecology Notes 7: 965-968. 